Portland State University

PDXScholar

$1-1-2012$

\title{
A Proposal for a Track-II Coalition in the Middle East: Creating the Conditions for Regional Dialogue, Public Engagement, and Security Cooperation
}

Mart Stewart-Smith

Portland State University

Follow this and additional works at: https://pdxscholar.library.pdx.edu/honorstheses Let us know how access to this document benefits you.

\section{Recommended Citation}

Stewart-Smith, Mart, "A Proposal for a Track-II Coalition in the Middle East: Creating the Conditions for Regional Dialogue, Public Engagement, and Security Cooperation" (2012). University Honors Theses. Paper 12.

https://doi.org/10.15760/honors.12

This Thesis is brought to you for free and open access. It has been accepted for inclusion in University Honors Theses by an authorized administrator of PDXScholar. Please contact us if we can make this document more accessible: pdxscholar@pdx.edu. 


\section{A Proposal for a Track-II Coalition in the Middle East}

Creating the Conditions for Regional Dialogue, Public Engagement, and Security

Cooperation

Mart Stewart-Smith

Hatfield School of Government

Spring 2012 


\begin{abstract}
This paper analyzes the state of Middle East Track-II projects since the 1990s, the failure of the ACRS working group, and how a better understanding of security norms and public opinion can improve Track-II collaboration and produce long-term results. The first section of the paper provides a summary of NGO activities, and how their work relates to the development of a regional security regime. The projects featured in this paper are by no means exhaustive, but are intended to represent the variety of forms and objectives Track-II efforts have traditionally taken in the region. The second section provides a review of perspectives on international norm diffusion and the influence of public opinion on policymaking. Building on this foundation, the third section provides an outline of the goals, structure and composition of an unofficial regional security coalition between NGO partners in the Middle East.
\end{abstract}




\section{Table of Contents}

$\begin{array}{ll}\text { LIST OF ABBREVIATIONS } & 4\end{array}$

$\begin{array}{lr}\text { INTRODUCTION } & 6\end{array}$

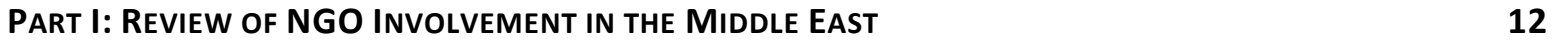

- What are Track-II Negotiations? 12

- The Institute on Global Conflict and Cooperation 15

- The american Academy of Arts and SCIences 16

- $\quad$ the aAas Center for Science, Technology, and Security Policy 18

- the Chemical Weapons Convention Coalition 20

- The Stockholm International Peace Research Institute 21

- The Search for Common Ground 23

- The Cooperative Monitoring Center 25

Part II: Building a Regional Security Coalition: The Application of Theory 26

- Security Regimes: Theory and The Middle East 29

- $\quad$ Security Norms $\quad 39$

- Public Opinion, education, and Security Policy 56

PART III: The Goals, Structure, ANd EnCUmbrances OF A Track-II Coalition 67

$\begin{array}{ll}\text { - Track-II VS. Track-I } & 67\end{array}$

- Goals $\quad 70$

- Structure and Function $\quad 73$

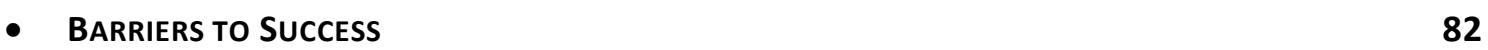

$\begin{array}{lr}\text { CONCLUSION } & 85\end{array}$

$\begin{array}{lr}\text { BIBLIOGRAPHY } & 87\end{array}$ 


\section{List of Abbreviations}

AAAS The American Academy of Arts and Sciences

AAAS The American Association for the Advancement of Science

CBM confidence building measure

CCFR Chicago Council on Foreign Relations

CMC Cooperative Monitoring Center

COE Council of Europe

CSBM Confidence- and Security-Building measure

CSCAP Council on Security Cooperation in the Asia Pacific

CSTSP Center for Science, Technology, and Security Policy

CWC Chemical Weapons Convention

CWCC Chemical Weapons Convention Coalition

FIS Foundation for International Security

ICPME Initiative for Peace and Cooperation in the Middle East

IGCC the Institute on Global Conflict and Cooperation

IGO Intergovernmental Organization

IPCRI Israel Palestine Center for Research and Information

MENA Middle East and North Africa

NGO Non-Governmental Organization

OPCW Organization for the Prohibition of Chemical Weapons

OSCE Organization for Security Co-operation in Europe

PLO Palestinian Liberation Organization

SFCG Search for Common Ground

SIPRI Stockholm International Peace Research Institute

UCLA University of California, Los Angeles 
UNIDR United Nations Institute for Disarmament Research

WMD weapons of mass destruction

WMDFZ weapons of mass destruction free zone 


\section{Introduction}

This paper is an attempt to address shortcomings in existing Middle East security regime literature by providing a short-term recommendation for how to influence the long-term future of Middle East security. The primary components of the paper include a concise review of notable NGO activities in the Middle East since the early nineties, an analysis of prominent perspectives on security regime development, international norm development and diffusion, and the relationship between public opinion and policymaking. From this foundation, the last section of the paper outlines the goals, structure, and composition of an unofficial NGO coalition for the Middle East, including a consideration of the barriers to developing such a coalition.

Through this approach to Middle East security and diplomacy, I hope to get around some of the recurring hurdles common to discussions of the Middle East, both in the media and academia. For example, consider a recent publication from the James Martin Center for Nonproliferation Studies, "Seizing the Opportunity to Create a WMD-free Middle East."1 The article hails an upcoming conference in Finland as a possible "cornerstone for a new regional security architecture" for the Middle East. The path to success through this official forum is supposed to be simple: first, participation from every state in the region must be secured, including that of Iran and Israel; second, all participants must demonstrate a readiness to compromise on reasonable guidelines for regional cooperation; finally, extra-regional sponsor states (the United States, Russia, and the United Kingdom) must demonstrate a commitment to the principles a goals developed by the regional participants. Summits of this sort are not unique. Time and again governments agree to meet, with varying degrees of regional inclusivity,

\footnotetext{
${ }^{1}$ Tamim Khallaf (2012). "Seizing the Opportunity to Create a WMD-free Middle East" found online at http://cns.miis.edu/wmdjunction/120417_mideast_wmdfz.htm last accessed May 18, 2012
} 
and they stumble over the same issues in each instance. The cycle continues. Governments meet, disagree on guiding principles, and progress fades.

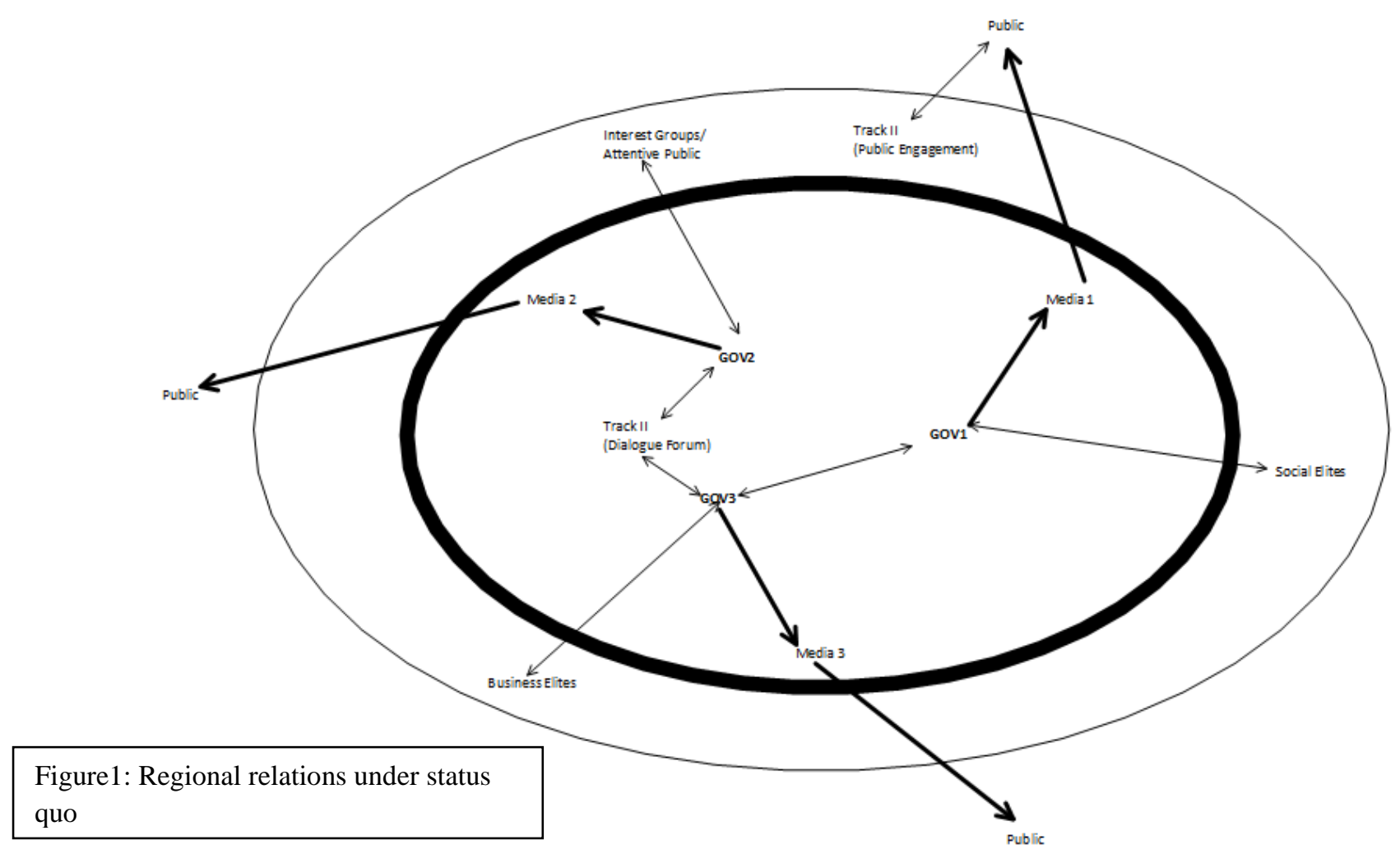

Figure 1 is a simplified representation of the interactions between various official and unofficial institutions under the status quo. The three governments portrayed above interact with elite members of the public, identified above as business elites, social elites (this may include religious leaders or media figures), and interest groups (including the "attentive public" which will be examined later). In this model, NGOs and the track II projects they sponsor have little room for influence. In some cases they are permitted to interact with government officials, or they sponsor public engagement programs, but in both cases they operate in isolation from other NGOs, and so have only a limited sphere of influence. On the periphery are the regional publics, informed exclusively by media inputs with little or no recourse for policy engagement. Note that 
media entities are highly influenced and controlled by governments. As a simplified model there are of course exceptions, but as a portrayal of security relations in the Middle East, this provides a useful visualization of the last few decades of security negotiations.

Official approaches under the status quo, in the framework illustrated in figure 1 , fail for two reasons not usually addressed by contributors to security policy literature. First, before progressive concessions can occur, and guiding principles for a regional security regime can be agreed upon, there must be a unified, normative foundation in the region. States must agree on certain norms of military and diplomatic behavior. These norms need not be as deeply rooted as they are, for example, among European states, but they must at least be widely accepted in the region. Secondly, regional publics are often opposed to dramatic changes in security relations between adversarial governments; most notably consider Israel, Palestine, Syria, Egypt and Iran. To illustrate this point, at points later in the paper I discuss examples from both the failure of talks sponsored by the Search for Common Ground in 1993, and later, the failure of Camp David talks in 2000 .

By describing a NGO coalition model for the Middle East, this paper attempts to provide a possible solution to both the norms and public opinion barriers by turning to regional NGOs and the potential for expanding and integrating track II projects. Before exploring details of an NGO coalition in the Middle East, consider the following example from the Asia Pacific region. The Council on Security Cooperation in the Asia Pacific (CSCAP) is a network of security institutes who help structure and guide a regional discourse on security policy. ${ }^{2}$ The Council was founded in 1993 after a meeting of two dozen security institutes from ten countries (Australia, Canada, Indonesia, Japan, South Korea, Malaysia, the Philippines, Singapore, Thailand, and the

\footnotetext{
${ }^{2}$ Council for Security Cooperation in the Asia Pacific. 2012, last accessed May 1, 2012 <www.cscap.org〉.
} 
USA) determined that a coordinated effort would provide a useful perspective on the securityrelated proceedings of ASEAN. The CSCAP attends to a variety of issue areas, including CSBM, comprehensive and cooperative security, transnational crime, maritime security cooperation, and preventive diplomacy. Four working groups are currently operating under the CSCAP: Cybersecurity as a central strategy for securing the cyber environment in the Asia Pacific region, water resources in mainland Southeast Asia, multilateral security governance in Northeast Asia/North Pacific, and countering the proliferation of weapons of mass destruction in the Asia Pacific. The existence and success of the CSCAP is a hopeful sign for developing a similar organization in the Middle East, however the existing organization and the proposal for the Middle East differ in one important way. The unofficial network of NGOs in East Asia was founded in the wake of ASEAN, a stable and effective official regime. This ordering of events has an effect on the activities of the NGO coalition by way of the level of support received from host governments. The CSCAP is intended to augment the ongoing work of government collaboration, whereas in the Middle East, the NGO coalition would spend considerable time working to create government collaboration, in the hope of someday establishing an organization similar to ASEAN. The lesson of the CSCAP is that an NGO coalition can work, but it should be understood that the task in the Middle East will be more challenging. Consider figure 2 for a visualization of how an NGO coalition can successfully overlay with government, media, and public relations in a region. 


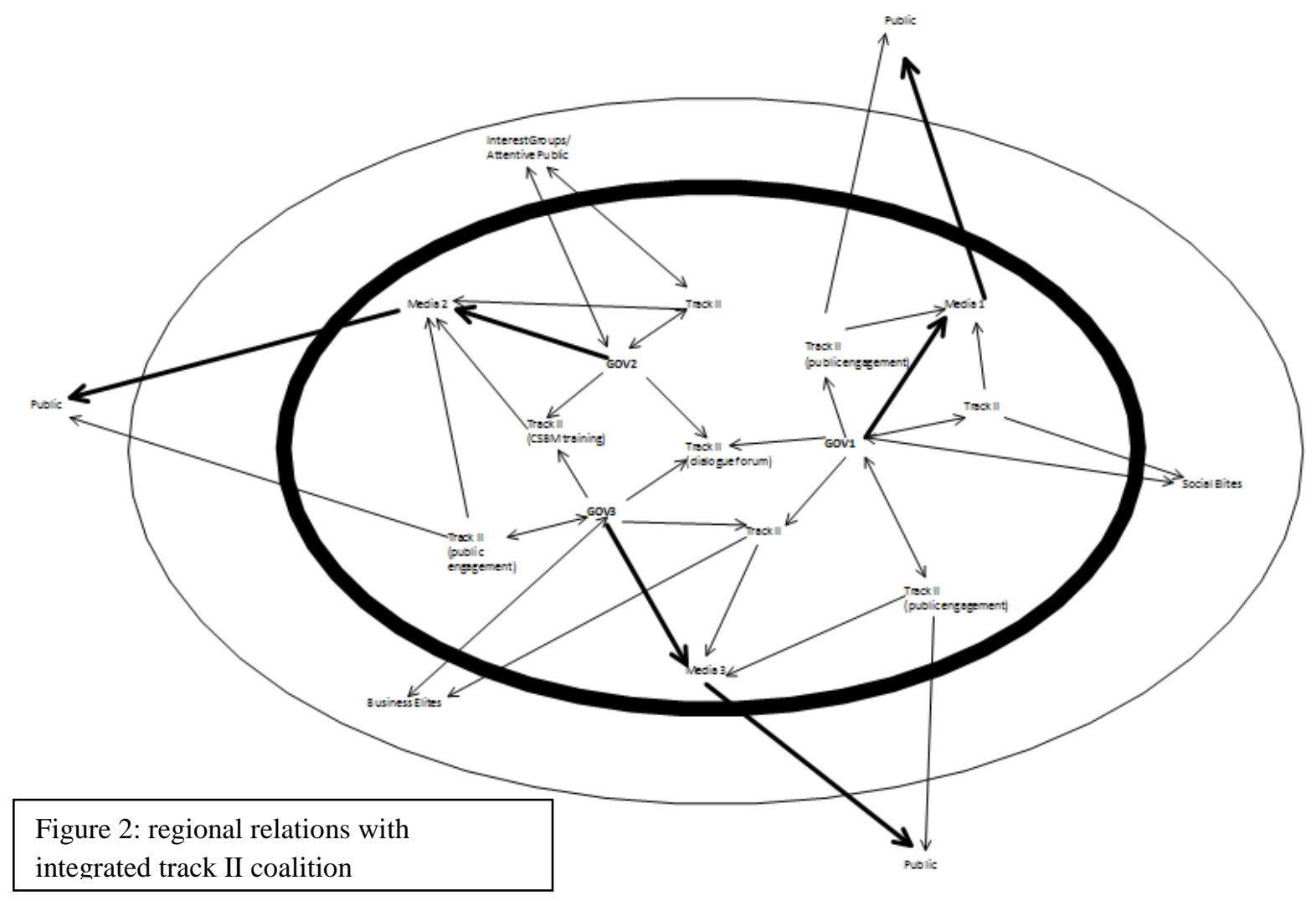

Figure 2 provides a visualization of regional relations with the development of an unofficial NGO coalition. First, it should be noted that the increased number of track II projects in figure 2 compared to figure 1 is not necessarily an increase in the number of NGOs operating in the region, but is instead intended to illustrate the sustained presence of track II projects that are integrated in the coalition. As I will discuss later, one of the greatest failings of current NGO projects is the inability to sustain a given project beyond a handful of meetings and, in some cases, a single publication. The advantage of the integrated track II approach is the ability to create a sustained regional presence through coordination between coalition participants and the sharing of resources. Figure 2 shows a selection of possible types of engagement offered by existing track II projects, each of which are strengthened by participation in the coalition. Some projects focus specifically on public engagement, others work to provide a forum for regional 
dialogue between government and NGO representatives. Perhaps most importantly is the increases communication with regional media outlets provided by the collaborative efforts of the coalition. The thickness of the arrows in figure 2 indicates the differences in influence and media saturation that can be achieved by governments as compared to NGOs. A comparison of figures 1 and 2 shows the intended effect of the track II coalition proposal.

When track-II projects in the Middle East have occurred over the last two decades they function almost identically as their official counterparts, especially in cases where government representatives are present. Because they operate the same way, these projects are vulnerable to the same weaknesses inherent in government relations. State interests and entrenched rhetoric keep governments in the Middle East apart. Track-II programs ought the be able to capitalize more effectively on what makes them fundamentally different from official government programs; NGOs are not restricted by state interests, their current operations show a willingness to engage across the region, and their work makes an effort to transcend debilitating state rhetoric. In order to better realize the potential of these attributes it is necessary to forge a coalition of NGO partners that is regionally inclusive and that can lay a foundation for a future of stable government relations. In examining the existing work on regime theory, norm diffusion, and public opinion, the remainder of the paper discusses how the coalition ought to operate (as depicted in figure 2) and what NGO cooperation stands to achieve. 


\section{Part I: Review of NGO Involvement in the Middle East}

\section{What are Track-II Negotiations?}

Track-II negotiations, track-II diplomacy, or citizens' diplomacy describe activities in which nongovernmental organizations (NGO) engage in dialogue to address policy issues traditionally reserved for governments. In contrast, track-I negotiations are those between official government representatives. Three stages exist in the track-II process: socialization, filtering, and policy realization. ${ }^{3}$ In the first stage, the typically small group of participants in track-II dialogues, involving primarily individuals affiliated with NGOs, but sometimes including government elites acting in an unofficial capacity, begins discussing a specific policy issue. If the dialogue is successful, a sort of group socialization occurs in which direct participants in the dialogue are more supportive of the conclusive recommendation than their counterparts who did not participate. The second stage, the filtering process, involves the translation of policy recommendations to the outside world. Typically this involves participants returning to their respective countries and working with government officials to build consensus in support of the track-II recommendation. The final stage, which is often not achieved, is the successful enactment of the policy recommended by the track-II participants.

The remainder of this section reviews some of the most notable track-II activities in the Middle East since the early 1990s. With the end of the Madrid peace process, and later the collapse of the Arms Control and Regional Security (ACRS) working group, a variety of unofficial educational projects, conferences and summits were sponsored by newly formed

\footnotetext{
${ }^{3}$ Dalia Dassa Kaye, Talking to the Enemy: TrackTwo Diplomacy in the Middle East and South Asia (Santa Monica, CA: RAND National Security Research Division, 2007) xii
} 
organizations and coalitions. Although many of these efforts operated independently from each other, with differing missions, funding sources, and participants, the overarching motivations were often similar; in the absence of official dialogue, it was vital to maintain communications between policymakers and other elites in the region in order to keep the peace process alive and prevent region from becoming increasingly fractured. One of the most detailed accounts of Middle East Track-II efforts is presented by Dalia Dassa Kaye. For a more exhaustive account of activities in the 1990s, see Michael Yaffe's earlier publication. ${ }^{4}$

Track-II events in the Middle East are typically in the form of unofficial diplomatic meetings between security elites and academics. In some cases the purpose of the event is to produce a research report on specific security-related subjects. Distribution of these reports is usually limited to governments, policy research institutes, and other elite stakeholders. Although many participants in Track-II events acknowledge the importance of communications with the media about their activities, this facet of dissemination is often the most lacking, while potentially being most crucial. ${ }^{5}$ Track-II dialogues and research endeavors engage with a variety of subject areas relating to security studies, including, but not limited to military technology, military communication, economics, development, resource scarcity, and religion. Discussion and analysis of each of these subjects can vary depending on the regional scope of the approach. Peter Jones divides track-II activities in the Middle East into three categories. ${ }^{6}$ First, there are projects that pursue sub-regional security arrangements by engaging exclusively with either Gulf or Mediterranean states. Second are those seeking to establish a region-wide security regime,

\footnotetext{
${ }^{4}$ Kaye 2007; Michael D. Yaffe. 2001. "Promoting Arms Control and Regional Security in the Middle East," Disarmament Forum, 2001; Peter Jones. "Filling a Critical Gap, or Just Wasting Time: Track Two Diplomacy and Regional Security in the Middle East," Disarmament Forum, 2008.

${ }^{5}$ Interview with Paul Walker (Ph.D.), August, 2011.

${ }^{6}$ Peter Jones, Towards a Regional Security Regimes for the Middle East: Issues and Options, report of the SIPRI Middle East Expert Group (Sweden: SIPRI, 2011) 47
} 
with the potential to develop sub-regional arrangements as components of the greater whole. Lastly, some efforts emphasize specific security-related subjects and do not address the scope of geographical participation. The case studies presented later in Part I include examples of each type of approach. For the proposed track II coalition, it will be important that examples of each type of approach are included. Looking back to figure 2 , recall that it is valuable to include a diversity of approaches to regional integration; certain NGOs focusing specifically on creating forums for policy dialogue, while partner NGOs assist in the dissemination of information to the public. Likewise is it valuable to include NGOs that operate regionally, sub-regionally, or in specific policy areas, as described by Jones. Each approach has certain strengths and none should be ruled out at the expense of another.

Before reviewing examples of NGO activities in the Middle East, it is worth noting that it can be difficult to identify specifics about the policy options under review at track-II events. Under the status quo, the political sensitivity of regional security is of concern for many of the elites who opt to participate in unofficial dialogues; information concerning the content of such discussion is often withheld from public scrutiny. This information asymmetry perpetuates the strained relations between publics and governments, and it is among the goals of the proposed coalition to provide an improved filtering process in order to break the pattern of failed track II projects. Of more immediate practical concern is the difficulty this presents when writing about track II projects. For this reason, the featured examples emphasize the subject issues, composition, and funding of each project, and only in some cases provide details concerning security policy proposals and analysis.

The following examples were selected not only for their notoriety, but for the diversity of their approaches. Each of the following Track-II initiatives represents an important role 
nongovernmental organizations are able to play in the Middle East. Many projects are of the traditional sort described above, involving an assembly of regional and extra-regional representatives who analyze security issues and develop policy recommendations. Within this traditional approach there are often important variances in regional inclusion, media interaction, and dissemination of results. Other approaches attempt to develop partnerships with NGOs expressing a common purpose in order to share in resources and to expand their influence. Still others focus on the technical side of regional security. These organizations work with regional leaders to facilitate either the sharing of technology or research collaboration with a design to build trust in the region and potentially create effective confidence and security building measures. Each of the following examples illustrate drawbacks and advantages to the Track-II approach to regional security, and will be informative in the later discussion of a track-II regional coalition.

\section{The Institute on Global Conflict and Cooperation}

Following the end of the Madrid peace process, the Institute on Global Conflict and Cooperation (IGCC) began hosting track-II events in the Middle East. ${ }^{7}$ The IGCC hosts events with the intention of building regional relationships between political elites. In the Early 1990s, the IGCC events mirrored the activities of the multilateral peace process, and therefore addressed a range of topics including arms control, regional security, the environment, water scarcity, refugees, and economic development. ${ }^{8}$ Following the collapse of the ACRS working group the IGCC began to focus exclusively on military dialogue, including force postures, military balance of power, weapons effects, arms control, counter proliferation measures, military ethics, and

\footnotetext{
${ }^{7}$ University of California Institute on global Conflict and Cooperation. 2011. <http://igcc.ucsd.edu/policy/track-iiforums/middle-east-dialogues.htm> last viewed on March 11, 2012.

${ }^{8}$ Kaye 2007. p36
} 
military education. The events with the largest scope are biannual meetings averaging 300 participants. These meetings draw professionals from every Middle Eastern country, Iran, Turkey, the United States, and a variety of European nations. Additional meetings include those between exclusively active and retired military personnel. Participants in these smaller dialogues include the same countries, with the exception of Iran, which has not had a military representative present at any of the recent meetings. The smaller meetings focus on specific diplomatic and security issues, many of which involve discussions of sensitive government information, and therefore reports are not made publicly accessible. The primary source of funding for these events historically comes from the United States and Greek governments.

\section{The American Academy of Arts and Sciences}

The most relevant events hosted by the American Academy of Arts and Sciences (AAAS) occurred in the early 1990s, but it should be noted that the AAAS continues to be involved in security dialogues in the United States, typically limited to U.S. policymakers and professionals. ${ }^{9}$ The first Middle East meeting hosted by the AAAS was in $1992 .{ }^{10}$ Around this time the AAAS also participated in joint efforts with the Foundation for International Security (FIS), which hosted an event in June of 1992 in Adderbury, England, and the Israel Palestine Center for Research and Information (IPCRI), which hosted an event in London in October 1992. The AAAS talks continued from 1992 to 1994 in six formal sessions. The focus of this series of talks was arrival at a settlement between Palestinians and Israelis on some of their most pressing security issues relating to the Israeli withdrawal from the West Bank. Participants in these

\footnotetext{
${ }^{9}$ The American Academy of Arts and Sciences. 2011. http://cstsp.aaas.org/event.html?bydatepast=1\&s=360\&np=33 last accessed on March 12, 2012

${ }^{10}$ Āghā, Ḥusayn, and Shai Feldman. Track-II Diplomacy: Lessons from the Middle East. Cambridge, MA: MIT, 2003.
} 
meetings included U.S. academics, only some of whom were directly affiliated with AAAS, Israeli academics, a retired Israeli government official, and Palestinian security experts, including one PLO official.

This project was notable for two reasons. Firstly, the format of the meetings allowed Israeli and Palestinian representatives to confer in a setting that placed their mutual security concerns on an equal footing. According to Hussein Agha (Agha et. al. 2003), the AAAS talks were unprecedented in that they allowed Palestinian security specialists to present their views to a specialized Israeli and U.S. audience. Prior to this experience, the security dialogue in the U.S., Europe, and Israel was dominated by an Israeli perspective on Middle Eastern security. This was an important opportunity to present the unique and often marginalized security concerns of the Palestinian leadership, given the asymmetry of power between the parties. The security concerns of both parties were considered "parallel prerequisites" to any possible settlement concerning an Israeli withdrawal. On the Israeli side these concerns included worries that the Palestinian Liberation Organization (PLO) would be unable to prevent an increase in military activities in the West Bank and Gaza, and that potential inter-Palestinian conflict could spill over into Israel. Palestinian security concerns focused on Israeli settlements, and in the same vein, the potential for conservative revanchism to influence future Israeli policies toward Palestine.

The second unique characteristic of the AAAS talks, and the most important with regard to later sections of this essay, is the distinction between two different meeting groups within the single process. This structure could be thought of as a small track-II channel within a broader, 
more inclusive track-II forum. ${ }^{11}$ Besides the main six meetings, there were smaller unofficial meetings which did not include AAAS moderators or U.S. academics, and instead provided an opportunity for Israeli and Palestinian representatives to discuss and clarify issues that may have arisen in one of the main sessions. Ultimately the AAAS process was overshadowed by the Oslo talks, and the PLO decided to minimize the potential for confusion by only participating in one negotiating process, and so declined to continue participating in AAAS meetings.

\section{The AAAS Center for Science, Technology, and Security Policy}

The Center for Science, Technology, and Security Policy (CSTSP) works to facilitate communication between members of the security and science and technology fields in order to foster a better understanding of intentions, objectives, modes of operation, and potential advancements. ${ }^{12}$ The CSTSP is presently in the planning process for a third and fourth round of meetings, to be located in Tunisia and Egypt respectively, between science and technology experts in the Middle East, North Africa, Pakistan, and Afghanistan. In a recent presentation, Dr. Gwenaële Coat, Senior Program Associate of the American Association for the Advancement of Science, discussed the purpose of these meetings in addressing critical issues pertaining to security and international collaboration in the biological sciences. ${ }^{13}$ At the first meetings in Jordan and Kuwait, scientists in the region identified three primary policy concerns. First, insufficient funding and institutional support for many doctoral and post-doctoral programs leads to ongoing "brain drain." Secondly, scientists and policymakers do not forge strong relationships, resulting in poor communication and coordination on vital policy concerns.

\footnotetext{
11 Ibid. p68

${ }^{12}$ AAAS Center for Science, Technology, and Security Policy.2011. http://cstsp.aaas.org/ last accessed March 12, 2012

${ }^{13}$ Information from a presentation by Dr. Gwenaële Coat and Dr. Chen Kane on July 15, 2011, hosted by the Global Green USA, Security and Sustainability Program in Washington, D.C. A summary of the event is available at http://globalgreen.org/press/194.
} 
Finally, there is not an established legal framework in the region to facilitate the exchange of expertise and research. The inability to effectively collaborate within the region hampers the capacity of research institutions and governments to respond to some of their shared problems, such as the spread of infectious and chronic diseases.

Certainly one of the smaller track-II projects currently operating in the Middle East, the CSTSP program nonetheless draws attention to the variety of security issues present in the region. At the same event as Dr. Gwenaële Coat's presentation, Dr. Chen Kane, Senior Research Associate of the James Martin Center for Nonproliferation Studies, presented a response to some of the concerns advanced in the CSTSP meetings. Kane proposed that the Middle East is uniquely disadvantaged compared to other regions because it does not have an established intergovernmental organization. Such a regional organization could bring governments together to collaborate on important security policies. Instead, it may be more feasible to move forward with either bilateral, sub-regional, or regional policy dialogues, so long as the "lowest common denominator" can be agreed upon. This entails identifying a common area of concern upon which a new policy regime can develop. Kane's four components of a successful process included (a) the identification of each state's threat perception, (b) engagement with local stakeholders at an early stage so that their involvement can help sustain the effort, (c) foreign parties participating in discussions must learn from past mistakes and avoid overstep, and lastly (d) a regional program must include the ability to track member progress and to verify that established policies have the desired effect. 


\section{The Chemical Weapons Conventional Coalition}

The Chemical Weapons Convention Coalition (CWCC) is a young and growing network of NGOs dedicated to the elimination of chemical weapons. The CWCC was founded in 2009 under the leadership of Global Green USA. The explicit mission of the CWCC is to promote the universality of the Chemical Weapons Convention (CWC). Currently the states remaining outside the CWC include Angola, Egypt, Israel, Myanmar, North Korea, Somalia, and Syria. The CWCC is included in this analysis because as an organization they have identified the Middle East as a priority, as three of the most influential states in the region are outside the Convention. On April 13, 2011, the CWCC held its second general session at the Technical Secretariat of the Organization for the Prohibition of Chemical Weapons (OPCW). The meeting included 19 NGOs from 14 countries in Africa, Asia, Europe, and the Americas. ${ }^{14}$ Today, the CWCC includes 50 members, with the hope of doubling membership within the coming year. ${ }^{15}$ Although they have yet to hold a summit of the Coalition in the Middle East, there are tentative plans for the summer of 2012.

The CWCC is notable, despite being relatively unproven as a Track-II arms control forum, because of its coalition structure. Hopefully, the CWCC network will be able to continue expanding, especially with regard to partnerships with NGOs and security studies program in the Middle East. As it stands, and as is the case with most Track-II projects, the biggest hurdle for the CWCC is the identification of funding sources. Global Green USA has submitted a variety of grant proposals to help support the potential 2012 conference, mostly to delegations to the

\footnotetext{
${ }^{14}$ The Organization for the Prohibition of Chemical Weapons, "OPCW Hosts Second General Meeting of the Chemical Weapons Convention Coalition.” April 15, 2011. Retrieved from http://www.opcw.org/news/article/opcwhosts-2nd-general-meeting-of-chemical-weapons-convention-coalition/ last accessed March 13, 2012

${ }^{15}$ Interview with Dr. Paul Walker Ph.D., Program Director, Global Green USA, Security and Sustainability Program.
} 
OPCW. The most substantial proposal is currently to Norway for $\$ 3$ million to support CWCC conferences over the next three years.

\section{The Stockholm International Peace Research Institute}

The Stockholm International Peace Research Institute (SIPRI) has contributed to Track-II projects in a number of ways since the 1990s, including working groups dedicated to developing confidence building measures for the Middle East, and the feasibility of constructing an electronic network for security and arms control issues. However, SIPRI made its most substantial contribution to Track-II efforts in the Middle East with their report analyzing the potential establishment of a Middle East security Regime. ${ }^{16}$ The report was the product of a series of meetings of an expert group which met four times from 1997 to 1998. Peter Jones, one of the more prolific writers in the area of Middle East security and Track-II negotiation, was the project organizer. After meetings were concluded, Jones toured the region distributing the report and sharing the conclusions of the expert group with regional parties. ${ }^{17}$ The report from the expert group was republished in 2011 to include a new introduction and afterward from Peter Jones.

The SIPRI report outlined a number of recommendations for the establishment of a regional security regime, starting with guiding principles. The first principle outlined in the report is the necessary establishment of regional security norms. These norms should provide the foundation for a security regime to address present and future policy concerns. These norms should "compliment and expand upon" the norms outlined by the United Nations Charter, but

\footnotetext{
${ }^{16}$ Kaye 2007

${ }^{17}$ Peter Jones. 2011. "The Arms Control and Regional Security Working Group: Still Relevant to the Middle East?" EU Non-Proliferation Consortium
} 
maintain relevance to the specific security conditions of the Middle East. The expert group made it explicitly clear in the report that they sought to avoid restricting the flexibility of states participating in the establishment of the security regime by creating overly burdensome guiding principles and prerequisites. The report also included some recommended steps toward a regional security regime. First and foremost, it will be necessary to make progress in the peace process before a viable security regime can be established, but regional policymakers should begin the process of developing a framework for a regime that would satisfy their particular interests. The regime, when established, will not include all regional parties. It will therefore be necessary to create a flexible, or "geometry variable" framework that will allow new membership, so long as they are willing to accept the already established principles of the existing regime. The issues identified by participants should account for all concerns of member states, but the timeline for addressing these concerns must be flexible.

The work of the expert group is also notable because of the composition of its membership. In geographical terms, many significant regional participants are accounted for: Egypt, Israel, Saudi Arabia, Dubai, Morocco, Jordan, Iran, Tunisia, and Turkey. Also included in the group were participants from Sweden, the United States, Canada, Brazil, and Russia. The composition of the group is well reflected in their report; the regional representation grounds the conclusions of the group firmly in an accurate presentation of regional conditions and sensitivities, while the extra-regional participants provided insight into precedent-setting security regimes with which they have prior experience. Although the participants did not include any official government contributors, many of them hail from institutes in their home countries specializing in security or defense studies. 


\section{The Search for Common Ground}

The Search for Common Ground (SFCG) is notable not only because of the organization's well established history of peace facilitation and advocacy, but because they maintain regional offices in the Middle East as part of their Middle East and North Africa (MENA) program. ${ }^{18}$ The SFCG currently maintains operations in Israel, Lebanon, and Morocco. Until recently they also had offices in Tunisia and Yemen. The SFCG work in Lebanon and Morocco focuses primarily on civil issues. Their office in Jerusalem, established in 2000, promotes the development of positive relationships between Palestinians and Israelis through a variety of multi-track programs. Many of the programs housed in the Jerusalem office emphasize media engagement and interfaith dialogue and advocacy. ${ }^{19}$

Although the project is no longer active today, the SFCG sponsored a program from 1992 to 1994 called the Initiative for Peace and Cooperation in the Middle East (IPCME), now known as the as the Search for Common Ground in the Middle East. In this series of talks Israeli and Palestinian representatives developed a set of security arrangements that might have been successful in resolving the Syrian-Israeli peace process, if it had not been cut short. ${ }^{20}$ The SFCG was the only organization to have been successful in establishing a working framework for such a process. Unfortunately, in December 1993, talks were derailed by press leaks, and so prevented any real conclusion from being reached. ${ }^{21}$ Agha provides four critiques of the TrackII process in an attempt to explain the failure of this SFCG project. First, many of the Syrians participating in the dialogue had little experience with security policy, and so were poorly

\footnotetext{
${ }^{18}$ Search for Common Ground, Peacebuilding \& Conflict Transformation in the Middle East and North Africa. http://www.sfcg.org/mena/ last accessed March 13, 2012.

${ }^{19}$ Search for Common Ground, Jerusalem. http://www.sfcg.org/programmes/jerusalem/index.html Last accessed March 13, 2012

${ }^{20}$ Kaye 2007 p.40

21 Agha 2003 p.109
} 
positioned to usefully contribute to policy development. Second, Track-II negotiations are often extremely vulnerable to leaks. In the same vein, a third critique is the asymmetry between the parties. Israeli representatives were not official members of the government, whereas the Syrian participants were, thus making them significantly more vulnerable. Lastly, there were no clearly identified mentors. In Agha's approach, mentors are individuals who serve to both facilitate discussion and relay developments from talks back to governments and interested parties. Conflict resolution does not take place in a vacuum, so it is vital to maintain ongoing dialogue with parties not directly engaged in the process. In the absence of mentors, Track-II negotiations are likely to fall short of their potential.

More recently, the SFCG hosted Madrid +15, which took place in Madrid from January 10-12, 2007. The conference included representatives from Israel, Egypt, Syria, Lebanon, Palestine, Jordan, and Saudi Arabia. The conference was held in commemoration of the $15^{\text {th }}$ anniversary of the 1991 Madrid Middle East Peace Conference. The most touted result from the brief series of meetings was an agreement among the assembled parties that "there is a need to firmly reassert the spirit of Madrid 1991" and that "participants called for a return to negotiations and for an official International Peace Conference.” ${ }^{22}$ It is interesting to consider the differences between the two projects. The 1993 talks were considered a failure, whereas those in 2007 were an apparent success. Clearly, the difference is not the product, but the scope and ambition of the goals set out to guide the two processes, by which failure or success are determined.

\footnotetext{
${ }^{22}$ Search for Common Ground, Jerusalem. http://www.sfcg.org/sfcg/sfcg madrid.html Last accessed May 20, 2012
} 


\section{The Cooperative Monitoring Center}

Sandia National Laboratories opened the doors of the Cooperative Monitoring Center (CMC) in 1994 with the hope that if more security experts in more countries were made aware of available monitoring technology, they might be more amenable to regional security arrangements. Few countries, especially those in the Middle East, possess the resources and technical expertise necessary to develop monitoring technology that could provide verification of arms control regime adherence. ${ }^{23}$ During the 1990 s the role of CMC was largely educational. In July 1994, the CMC hosted a workshop attended by representatives of military, governmental, and academic institutions in Israel, Egypt, Qatar, Oman, and Kuwait. The purpose of the workshop was to provide a forum in which regional leaders could meet with each other and representatives from the U.S. to share monitoring techniques and technology. ${ }^{24}$ The hope was to provide a foundation for the development of confidence and security building measures that could support an eventual arms control agreement or a new regional security regime. In 1996, the CMC hosted representatives from Egypt, Jordan, and Israel to review options for a Weapons of Mass Destruction Free Zone (WMDFZ). A number of similar events took place throughout the 1990s and into the early 2000s, some of which were in partnership with government departments (e.g. U.S. Department of State, U.S. Department of Energy).

In October of 2003 a new CMC opened in Amman, Jordan. In a region of the world more prone to violent conflict and cold government relations, the mission of the center was to

\footnotetext{
${ }^{23}$ Arian Pregenzer. "The Cooperative Monitoring Center: The First Ten Years." International Security News 4.3 (2004): 2-21. Sandia National Laboratories, July 2004. Web. 1 Mar. 2012. <http://www.cmc.sandia.gov/isn/jul04isn.pdf>.

${ }^{24}$ Kaye 2007 p43
} 
promote a culture of trust. ${ }^{25}$ Many of the activities hosted by the CMC in Amman are modeled after its predecessor at Sandia. The specific regional issues emphasized by the center include border security and management, non-proliferation of WMD, public health, resource management, and environmental security.

\section{Part II: Building a Regional Security Coalition: The Application of Theory}

As illustrated by the expert group in the SIPRI report, and reiterated by Peter Jones in the 2011 republication of their report, one of the primary goals of a regional security regime should be the development of new security norms. ${ }^{26}$ By allowing parties to the regime to collaborate on their shared concerns, new behaviors will spread and gradually become the natural means of interaction between governments. Unfortunately, given the current political state of the Middle East, there are only three paths to the establishment of a security regime. The first, and most likely, is the creation of a small coalition of states who will set out semi-inclusive guiding principles that would allow the coalition to grow until it encompasses each state in the region. Unfortunately, the creation of such a regime today would likely develop along existing political lines, and fail to grow into an inclusive body. A second, and more abstract approach, would require multiple instances of extraordinary political leadership and risk-taking. If the political leadership of Israel, Syria, Egypt, and Iran were to jointly decide to enter into a security arrangement, including monitoring systems and an array of confidence building measures, it

\footnotetext{
${ }^{25}$ Pregenzer 2003 p. 12
}

${ }^{26}$ Jones 2011 (B) 
would almost certainly provide a foundation for a regionally inclusive regime. Of course, the confluence of conditions necessary for this approach to be successful is unlikely enough to be prohibitive. Consider the well-known example of the 1979 peace treaty between Egypt and Israel, the product of the previous year's negotiations at Camp David. Signed in Washington D.C. by Egyptian President Anwar Sadat and Israeli Prime Minister Menachem Begin, the 1979 treaty was an unprecedented step forward for Middle East peace negotiation. Although in some regards this is an example of the sort of political leadership necessary to forge a regional security regime for the Middle East, the path to 1979 is different in two important ways. First, both Egypt and Israel stood to gain much from closer relations with the United States following the treaty, and secondly, the complexity of a bilateral treaty is hardly comparable to an inclusive multilateral approach. It would have been impossible in 1979, or at least substantially more difficult, to pass a treaty including Syria and Iraq, just as today it is an overwhelmingly daunting task to develop a treaty including Syria and Iran.

Finally, the third possible approach would be facilitated by a network of NGOs. In similar fashion as the first option, the network could settle on certain guiding principles that would provide a foundation for an unofficial security regime. The hope driving this sort of unorthodox proposal is that within most nations of the Middle East, there exist organizations and parties who have several advantageous characteristics: they have less at stake than governments when participating in regional dialogue, they have greater credibility than authoritative and often corrupt governments, and who possess a willingness to engage with their regional counterparts. In contrast, the last half-century of Middle East relations was dominated by debilitating state interests and a frequent unwillingness to compromise and engage. The unofficial approach, although it suffers from a number of possible setbacks of its own sort, would provide a setting 
for the development of new security norms that would provide a framework for building an official equivalent.

The purpose of this section is to develop a theoretical framework for the effective operation of a collaborative NGO effort in the Middle East. The section begins by reviewing different perspectives on the operation and purpose of security regimes. Divided into two broad categories, examples of security regimes include Intergovernmental Organizations (IGO), the purpose of which are to create collaborative communities which coordinate efforts on a variety of policy issues (e.g. NATO, OSCE, etc.), and more restrictive security regimes based on the enforcement of a single shared policy interest, often relating to arms control or disarmament (e.g. CWC, BTWC, NPT, SALT). Discussion of the issues surrounding a Track-II security coalition in the second section will incorporate the substantial body of literature concerning the development, transmission, and diffusion of security norms. In the third section, I analyze the educational role of a Track-II security coalition as it pertains to security policy. Much of this section is concerned with the role of public opinion in the formation and enactment of security and foreign policy, and so will discuss how the coalition might undertake a moderating role between publics and governments. As moderators, NGOs can facilitate both the transmission of public opinion to policymakers and, through educational track II programs, better familiarize regional publics with complex regional security issues. As much of the existing research concerning public opinion and security policy is grounded in data from the United States electorate, and uses voting trends to support its various conclusion, it is an important component of this section to both attempt to translate some of this work to the conditions observable in the Middle East, and to propose new areas of quantitative research in the field. 
The following section builds on the theoretic framework presented in Part II to elaborate on the mechanics, composition, and goals of a proposed track-II security coalition. This section further develops perspectives on the establishment and growth of a coalition, focusing on the flexibility and adaptability of the model. There is also a discussion of practical concerns, such as voting processes, strategies for policy collaboration, and perhaps most importantly, funding.

\section{Security Regimes: Theory and the Middle East}

There are a variety of differing perspectives on how security regimes should best function, and the role they play in international relations. Better understanding security regimes will allow us to consider the development of a track II coalition that is intended to replicate certain functions and goals of an official security regime. I include three definitions of security regime which encapsulate the variety in the field. A traditional definition is provided by Robert Jervis. A security regime in this view consists of "those principles, rules, and norms that permit nations to be restrained in behavior in the belief that others will reciprocate." 27 This definition represents the realist perspective on international security by emphasizing balance of power and the role of competition between states. Building from his definition, Jervis articulates a model for a security regime, the primary purpose of which is to restrict the behavior of participants. Later definitions will allow more room for the understanding that security regimes ought to function as facilitating arrangements for inter-state cooperation. The cooperative perspective is more applicable to the track II model to be presented later, and should take precedent of Jervis' realist perspective. The most general and accommodating definition comes from Stephen Kranser; regimes are "institutions possessing norms, decision rules, and procedures which

${ }^{27}$ Robert Jervis. "Security Regimes." International Organization 36.02 (1982): 357 
facilitate a convergence of expectations. ${ }^{" 28}$ This definition is particularly helpful because it emphasizes the core components of a security regime - norms, rules, and convergence - rather than tying the definition to a set of activities, institutional structures, or the types of relationships existing between member states. If there were an opposite perspective to Robert Jervis, it would be Janne Nolan, who specifically describes the cooperative function of a security regime. "Cooperative engagement is a strategic principle that seeks to accomplish its purposes through institutionalized consent rather than through threats of material or physical coercion." ${ }^{29}$ Nolan's definition of a security regime organized around a cooperative purpose is most appropriate for an unofficial coalition. In her text, Nolan uses Western Europe to illustrate the ideal operation of a cooperative organization. Although conditions in the Middle East are significantly more complex than those in Western Europe, making it difficult to draw useful parallels, cooperation is the appropriate priority in both regions. Many scholars of Middle East security lean more towards the realist approach, and in some cases they are right to do so, but only when evaluating official security regimes in the absence of a track II foundation. For an unofficial coalition, cooperation and the encouragement of regional diplomacy and the building of political ties between governments and civil society is of paramount concern.

Regardless of definition, the core of a security regime is a shared set of norms. These can be norms of military engagement, norms of diplomatic engagement, or social norms. It may be useful to think of security regimes as institutionalized norms. ${ }^{30}$ For example, consider the evolution of the norm against chemical weapons. Chemical weapons have rarely been deployed

\footnotetext{
${ }^{28}$ Stephen D. Krasner. International Regimes. Ithaca: Cornell UP, 1983; Peter J. Katzenstein, Ronald L. Jepperson, and Alexander Wendt. "Norms, Identity, and Culture in National Security." Ed. Peter J. Katzenstein. The Culture of National Security: Norms and Identity in World Politics. New York: Columbia UP, 1996. Print.

${ }^{29}$ Janne E. Nolan. Global Engagement: Cooperation and Security in the 21st Century. Washington, D.C.: Brookings Institution, 1994.

${ }^{30}$ Jepperson, Wendt and Katzenstein 1996
} 
since they were first introduced to the theater of war. These infrequent but devastating instances most notably include World War I and the Iran-Iraq war. ${ }^{31}$ Since their invention, the use of chemicals in warfare was been an international taboo, explaining why so few cases exist in which they have been deployed. This near universally accepted norm was the foundation for the CWC, which is a type of security regime relating specifically to arms control. ${ }^{32}$

The common thread binding all effective security regimes together is the existence of confidence- and security-building measures (CSBM). As with security regimes, there are competing definitions of confidence building measures. In a study of Middle East CSBM Yair Euron provides a definition. "CSBM are measures taken in the strategic-military arena that regulate the military behavior of states in conflict, leading to the reduction of uncertainty on both sides in regard to: general military escalation, crisis escalation, surprise attacks, and low-level violence." 33 This understanding of CSBM emphasizes the role of the military and the transition from active conflict to detente. Particularly in regard to the Middle East, contributors to the field tend to favor CSBM that engage militaries in information-sharing, intelligence, crisis simulation, and joint training exercises. However, once again it is necessary to take a different approach to confidence building when considering the role of track II projects. A more inclusive perspective is provided by Michael D. Intriligator. CSBM include "political, economic or other activities...whether unilateral, bilateral, or multilateral." ${ }^{34}$ This approach is closer to the sense used in this paper. However, because an unofficial coalition cannot make policy governing

\footnotetext{
31 Jonathan B. Tucker. War of Nerves: Chemical Warfare from World War I to Al-Qaeda. New York: Pantheon, 2006.

${ }^{32}$ For further examples of security regimes, consider the extensive body of literature covering these existing regimes: NATO, OSCE, WEO, ASEAN, NPT, SALT, BTWC, etc.

${ }^{33}$ Evron, Yair. "Confidence- and Security-building Measures in the Arab-Israeli Context." Contemporary Security Policy 16.1 (1995): 152-72.

${ }^{34}$ Intriligator, Michael D. "Arms Control and Confidence-Building in the Middle East: Policy Recommendations in Three Phases." Ed. Steven L. Spiegel and David J. Pervin. Practical Peacemaking in the Middle East. New York: Garland Pub., 1995.
} 
military, economic or political actions, the arsenal of CSBM is greatly reduced. As is discussed in the section outlining the structure and composition of the proposed coalition, the primary goal ought to be the facilitation of regional political engagement. The CSBM employed in the early stages of regional cooperation should appropriately be limited to dialogue. From this foundation it will be easier to build more advanced and potentially compromising CSBM in the areas of military affairs, governance, and economics.

The application of CSBM came into its prime during the détente period of the Cold War as the United States and the Soviet Union began to negotiate arms limitations and verification protocol. Following the collapse of the Soviet Union, multilateral CSBM were used in Eastern Europe, and were not limited to the great power arrangements of the Cold War. ${ }^{35}$ These activities can be divided into three categories: communication, physical measures, and military behavior. $^{36}$ Communication, the most important general category for our consideration, should itself be broken into two parts. First is the communication between government officials acting in a diplomatic capacity. By engaging in dialogue, leaders build important relationships with each other, which help support cooperation and trust between governments. The second part of communication, which is more common in CSBM literature, encompasses a variety of information-sharing activities. Returning to the earlier example of U.S.-Soviet arms reduction agreements, an important component of these sorts of arrangements are verification procedures that include sharing force posture information, including the number of weapons stockpiled, delivery systems, etc. The second category, physical measures, includes primarily geographic concerns. Euron finds the establishment of demilitarized zones as the most common CSBM in this category. Finally, CSBM in the military behavior category include such things as rules of

\footnotetext{
${ }^{35}$ Evron 1995 p.159

${ }^{36}$ Ibid p. 152
} 
engagement, collective training exercises, and other activities having to do specifically with interactions between military institutions. Intriligator provides a list of 22 proposals for confidence building in the Middle East. ${ }^{37}$ The preponderance of the proposals draw from prior efforts in the region relating to weapons technology, delivery systems, communications, warning and surprise attack procedures, accidental or inadvertent war, and both legal and illegal arms shipments. These CSBM are divided into three phases for implementation, and despite being nearly two decades old, many are still relevant and worthy of consideration.

Related to the types of CSBM incorporated into security regimes, Steven Spiegel provides a useful breakdown of the different operating levels of a security regime. ${ }^{38}$ Spiegel considers three distinct levels: systemic, domestic, and individual. The systemic level describes the way states interact as part of a network of competing interests. The systemic relationships between states influence their behavior in pursuit of their interests, while also in some cases redefining states interests. The name of the next layer of interaction, the domestic level, is somewhat misleading. In his analysis of these interactions, Spiegel is concerned with interactions between bureaucracies, and the socializing effect these interactions can have. The domestic layer does not pertain to influences from the public. The domestic layer is at the heart of norm transference, one of the primary effects of participation in a security regime. The individual level encompasses interactions between political leadership. The socializing effect of these interactions is similar to the domestic level interactions. However, it is worth differentiating between bureaucrats and political elites because the socializing effect manifests differently on the two levels. On the domestic level, collaboration between government departments will influence the perspectives represented in the policy production process, and

\footnotetext{
${ }^{37}$ Intriligator 1995

${ }^{38}$ Spiegel 2004
} 
gradually bring the two governments nearer to consensus by adhering to certain norms. On the individual level, the important effect is the development of relationships between heads of state and other political elites. These relationships make leaders more inclined to cooperate with each other and increase the likelihood of further integration and cooperation. Beyond the three levels presented by Spiegel, it is necessary to include the public as a fourth. The reason this fourth layer is not already a standard component of security regime studies is the absence of institutionalized interactions between publics and governments in the context of existing security regimes; i.e. security regimes are the domain of government elites, and publics are only relevant to the extent they influence particular government members of a regime. The fourth layer is important to consider insofar as publics influence the behavior of their governments, a subject discussed at length in a later section. The influence of the public will be doubly important in the modeling of an unofficial coalition. One of the key roles of NGOs in security policy is to interact with the public, both to educate the public, and to advocate for public interest in their interactions with the government.

Returning now to security regimes, there are a number of ways to differentiate the various types of security regimes. Evron uses five categories in his analysis, ranging from the weakest integrated models, to the strongest, with the primary variances being the number of states involved and the number of agreed upon CSBM. Weakest in the list are security conventions. These regimes are informal arrangements (i.e. they are not organized around a codified treaty that articulates the goals and understandings of the parties involved) between states that do not maintain diplomatic relations. The primary enforcement mechanism here is unilateral deterrence. Qualified regimes are next, with either unilateral or mutual deterrence, and a complex network of CSBM. Third are normal security regimes. These arrangements are based 
on formal diplomatic relations between participants, and are also grounded in a network of CSBM. Common security regimes are similar to normal regimes, except the former includes multilateral arrangements (recall the CWC example) and are characterized by a greater degree of cooperation between participants. At the top end of the spectrum, cooperative security regimes maintain a very high level of cooperation between participants and adhere to a robust and penetrating set of CSBM.

In contrast to Evron, I choose to organize my consideration of security regimes around function, rather than the degree of integration. With Evron's approach, there is no end to the variances between the degrees of integration as you compare regions and historical periods, so the distinctions used by Evron are not particularly informative when trying to understand and contrast existing regimes. Furthermore, my approach is different because it does not offer a consideration of the fundamentally weak and almost non-existent regimes on the lower end of the integration scale. However, it is worth noting that the preponderance of security regimes that have existed in the Middle East since the mid-twentieth century have been of this sort: weak, bilateral, and short-lived. ${ }^{39}$

It is more useful to think about security regimes in four categories: legal, restrictive, cooperative, and allied. Within each category it should be understood that different regimes will maintain varying degrees of participant integration and cooperation. Legal regimes are those without a strong central organization to facilitate regime activities and dialogue. The best examples are weapon of mass destruction free zones (WMDFZ), such as the Treaty of Tlatelolco, the Treaty of Rarotonga, the Bangkok Treaty, and the Pelindaba Treaty, each of which are

\footnotetext{
${ }^{39}$ Evron describes Israeli-Syrian, Israeli-Egyptian, and Israeli-Jordanian regimes that existed during the 1950s and 1960s based on the Mixed Armistice Commissions. Following the 1960s, he discusses a series of bilateral agreements of varying degrees of integrity, usually beginning in the wake of conflict, and ending with the start of a new conflict.
} 
specifically regional nuclear-weapon-free-zones. There are also treaties banning the militarization of Antarctica, the seabed, and space. These treaties typically represent the codification of existing international security norms, and do not pertain directly to the settlement of a specific conflict. The CSBM included in legal regimes are verification measures agreed upon by regime members that enable them to confirm adherence to the norms established by the regime.

Restrictive regimes rely primarily on CSBM that involve military coordination. These are regimes discussed earlier in the realist model by Robert Jervis; the regime exists in a state of conflict, and the measures imposed by the regime are intended to restrict the behavior of its members in the mutually acknowledged interest of preventing future military conflict. Third, cooperative regimes are organized around cooperative principles. These regimes are not the byproduct of active conflict in the way of realist regimes. Cooperative organizations rely primarily on political coordination between governments to address regional issues. These regimes are likely to evolve out of the success of restrictive regimes, and so will maintain certain military CSBM. Examples of cooperative regimes include the OSCE and ASEAN. Lastly, the most integrated form of security regimes are those between allied countries. These regimes include collective security arrangements in addition to highly integrated CSBM, including shared military training exercises and shared technology. The most familiar example of this sort of arrangement is NATO.

As noted earlier, the Middle East has a history of short-lived, weak security regimes. The preponderance of these regimes were restrictive, as they were established in the wake of active military conflicts and were limited to military CSBM. However, founded in May 1981, the 
Cooperation Council for the Arab States of the Gulf (GCC) is a reasonably successful example of a cooperative regime. Consider the following description of the GCC goals:

The GCC Charter states that the basic objectives are to effect coordination, integration and inter-connection between Member States in all fields, strengthening ties between their peoples, formulating similar regulations in various fields such as economy, finance, trade, customs, tourism, legislation, administration, as well as fostering scientific and technical progress in industry, mining, agriculture, water and animal resources, establishing scientific research centers, setting up joint ventures, and encouraging cooperation of the private sector. ${ }^{40}$

As a cooperative security regime, the focus of the GCC is on economic integration, scientific collaboration, social programs, and other non-military issues. In the study of Middle Eastern security, the GCC is a useful example of how to build a successful regime, either through a regional structure, or as a network of sub-regional regimes including, and modeled after, the GCC. The obstacle faced by these proposals, which is often not addressed, is the differences in composition between either regional or sub-regional organizations. The GCC, compared the rest of the Middle East, is relatively homogeneous. Its membership includes the United Arab Emirates, the Kingdom of Bahrain, the Kingdom of Saudi Arabia, the Sultanate of Oman, Qatar, and Kuwait. Note that Yemen is not included among the membership, thus explaining the survival of the regime through intermittent diplomatic and military confrontations between Saudi Arabia and Yemen. A credible regional regime would require the membership of Israel, Syria, Iran, and Egypt (the participation of other states in the region is less controversial outside this central group). Likewise, a network of sub-regional regimes would require the participation of Yemen in the GCC, the inclusion of Israel in a Levantine organization, and participation from peripheral states such as Iran either as an independent state or a member of a regional group in

\footnotetext{
${ }^{40}$ Cooperation Council for the Arab States of the Gulf. http://www.gcc-sg.org/eng/index895b.html?action=SecShow\&ID=3 last accessed on March 2, 2012.
} 
West Asia. With either approach, inclusivity is a problem, and the model and precedent established by the GCC is unhelpful.

Security regimes face three types of problems, mostly having to do with the development stages, the most concerning of which is political instability. When entering into a security arrangement, a government will be less likely to accept a partnership that includes governments facing intense domestic opposition or which display instability within the regime. Spiegel's ${ }^{41}$ work identified both Saddam Hussein and Muammar Qadaffi as examples of unstable regimes which would make poor regime participants. In both cases, the elite political leadership appeared too far removed from the public to make them credible partners in a long term security arrangement. It goes without saying that Spiegel's choice of examples turned out to be particularly poignant. A second problem security regimes are prone to facing are dramatic shifts in economic conditions, both regionally, and when isolated in single member states. This is similar to political issues because poor economic conditions can result in public unrest and dissatisfaction with the government. However, in the case of public unrest resulting from an economic downturn, the onset of these conditions can be rapid and are usually unpredictable, and can destabilize an already establish regime. ${ }^{42}$ Finally, and of particular relevance to the Middle East, the balance of power between non-member states and member states in a region can influence the integrity of a security regime. In the context of the Middle East, this problem would likely arise if a regime were established that was not inclusive. For instance, if a security regime were created among exclusively Arab states, the divisions in the region would be exacerbated depending on Israel's perception of the new Arab organization. In this instance, the

\footnotetext{
${ }^{41}$ Steven L. Spiegel "Regional Security and the Levels of Analysis Problem." Ed. Zeev Maoz, Emily B. Landau, and Tamar Malz. Building Regional Security in the Middle East. London: Frank Cass, 2004.

${ }^{42}$ Ibid
} 
creation of a security regime would effectively worsen the security relations in the region, rather than improve them. The same argument can be made for including Iran in a security regime. In the Middle East, the threat of an arms race in response to a poorly considered security regime is very real, and should be deterrent enough to prevent the creation of a regime that lacks regional universality.

\section{Security Norms}

A norm is a standard of behavior that governs a group of actors of a particular, unifying identity. ${ }^{43}$ These standards of behavior exist as networks of inter-subjective understandings between actors. Academic discourse on norms span both political science and sociology, where political scientists typically emphasize the role of international norms in political society, and sociologists examine the role of social norms in everyday life. Among political scientists, liberals, constructivists, rationalists, and realists maintain four distinct perspectives on norm theory. ${ }^{44}$ In brief, the liberal perspective describes norms as providing incentives for social actors and political leadership to behave in a particular manner. In this way, norms constrain behavior. Constructivists believe that norms are learned by elites through interaction, and to that extent, they are shared understandings that constitute actor identities. The rationalist perspective differs in the provided understanding of norm propagation. Political elites decide to adhere to norms because of strategic interests. By understanding the process of norm propagation in this way, the realist perspective runs against a theory of norms where they spread by learning, or

\footnotetext{
${ }^{43}$ Martha Finnemore and Kathryn Sikkink. "International Norm Dynamics and Political Change." International Organization 52.4 (1998): 887-917. p984

${ }^{44}$ For a review of theoretical perspectives on norms, and how they overlay with perspectives on international and national security, see Jepperson, Wendt, and Katzenstein 1996 "Norms, Identity, and Culture in National Security" ed. Katzenstein, Peter J The Culture of National Security: Norms, Identity, and World Politics.
} 
where they constrain behaviors. Lastly, the realist perspective denies the existence of norms. Instead, realists describe larger behavioral trends with micro-level strategic calculations, where a belief in norms is an abstraction and should instead be considered as a network of interacting, independent choices. Understanding norms is useful when evaluating political behavior and social organization, and for the purposes of this paper, are particularly relevant to understanding how certain beliefs and behaviors can become standardized throughout a region.

Given that the primary focus of this paper is security policy in the Middle East, the reader should assume that unless otherwise stated, the norms under consideration are security norms. Furthermore, for the purposes of this paper, norms should be thought of as operating on two distinct but related levels. First, norms exist between states. These can be codified legal norms or norms that have developed through a history of state behavior and interaction. These sorts of international norms traditionally include rules of engagement in military conflict, diplomatic norms for interacting with foreign governments, behavior in international waters, the understanding of sovereignty and sovereign rights, etc. The second sort of norms are those among publics. As it pertains to security policy, these norms can be difficult to evaluate, primarily because the polity is a complex organization, and often cannot be discussed effectively as a unified whole. For this reason, norms existing on the national level ought to be considered in parts: elites, the attentive public, and the mass public. This division is particularly useful in the discussion of the transfer of norms between states and the diffusion of norms within states.

When studying the influence of norms, it is helpful to recognize that norms cannot be "bad" from the frame of reference of an adherent to a given norm. ${ }^{45}$ It is possible, from the perspective of an outsider, to make normative claims about the appropriateness or effectiveness

\footnotetext{
${ }^{45}$ Finnemore 1998
} 
of a given observable norm, but this sort of commentary is not helpful in understanding the character of a norm. A norm is a way of behaving, both among states and among individuals. Unlike a law or rule, a norm is not something that needs to be referenced to be understood by an adherent, but instead is accepted as a natural or given standard of behaving. More difficult to evaluate is the way in which this sort of standard is passed along. Although norms have a sense about them of being natural, they are clearly not. Instead they evolve through a socializing process which unlike with established norms, can involve a normative judgment from potential adherents.

Although there is a substantial body of work concerning the existence of norms, especially regarding their influence on international politics, considerably less has been said about the development of norms and how they are propagated. In this work, I lean heavily on the analysis presented by Martha Finnemore and Kathryn Sikkink in their 1998 collaboration, "International Norm Dynamics and Political Change."46 Of particular relevance, their work outlines a "lifecycle" of norm development. ${ }^{47}$ This lifecycle exists in four stages: norm emergence, realignment, norm cascade, and internalization. Three stages are from Finnemore and Sikkink, but in order to more effectively accommodate the Middle East, I include "realignment" as a separate second stage.

\footnotetext{
${ }^{46}$ Finnemore and Sikkink 1998

${ }^{47}$ Ibid p.895
} 


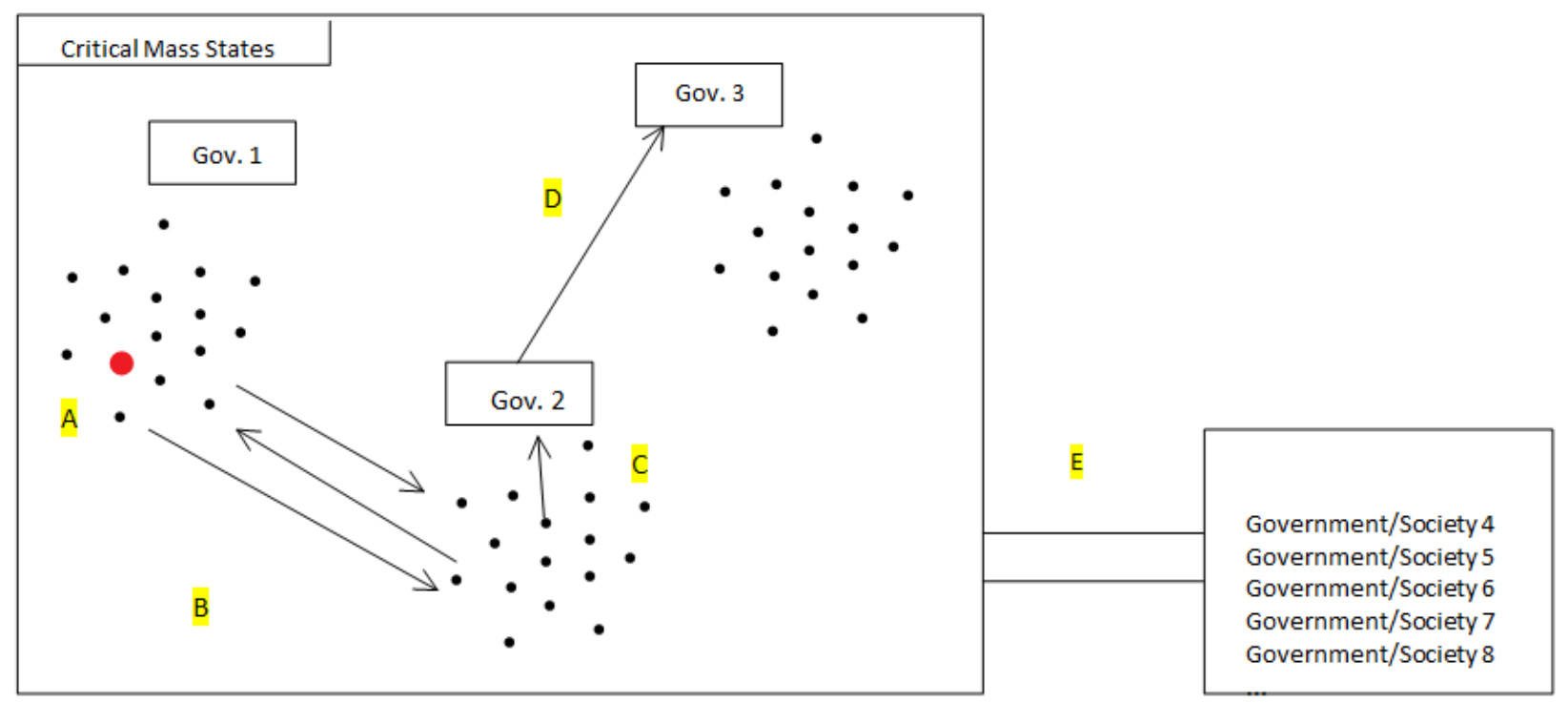

Figure 3: the processes involved in norm diffusion

Figure three provides a useful reference in understanding the process of norm diffusion. The process it depicts will become clearer in the following pages. In summary, part " $\mathrm{A}$ " identifies the beginning of the process at the norm entrepreneur, identified in the diagram by a red dot. Part "B" is the process throughout which norms are spread between publics through social institutions, and in the case presented in this paper, through NGO engagement projects. Part " $C$ " depicts the spreading of a norm from some segment of society, perhaps a social or economic elite, to government elites. Part "D" shows the process of norm diffusion through government interaction, a process also facilitated by NGO projects. Finally, part "E" shows the cascade of norms to other regional states after a critical mass of influential states is achieved.

The most important actor in the norm emergence stage is the entrepreneur. Although the originator of a particular norm could be thought of as a state, I restrict this part of the process to individuals. ${ }^{48}$ Restricting discussion of norm entrepreneurs to individuals will assist the coming

\footnotetext{
${ }^{48}$ For more on the role of states as norm originators, see Finnemore and Sikkink 1998; Jepperson, Wendt, Katzenstein 1996
} 
discussion of the Track-II security coalition and the role played by diplomats, bureaucrats, academics, analysts, and others participating in dialogue with foreign counterparts. Norm entrepreneurs identify specific concerns about an existing way of behaving. Norm entrepreneurs typically have an organizational foundation, are characterized by altruism, empathy, idealism and commitment, and use persuasion to propagate their ideas. ${ }^{49}$ Finnemore and Sikkink specifically identify issues of human agency, indeterminacy, chance occurrences, and favorable events as the origins for most norms. ${ }^{50}$ Issues identified at this stage in the formation of security norms involves a specific government practice or policy that develops within the context of the necessary originating conditions. In order for changes on this micro-level to develop into a new norm, the policy in question must be part of a broader network of similar policies. The reform of the parts can potentially lead to a change in norms.

Part of the role of a norm entrepreneur is to position an issue such that it is translatable to other individuals and states. David Snow refers to this process as "frame alignment." Much of this process has to do with the language used to describe an issue. By creating particular meaningful associations with an issue, the norm entrepreneur creates frames which organize collective experiences and influence the actions of potential norm adherents. ${ }^{51}$

The organizational platform of the entrepreneur is particularly important as an educational tool. NGOs and IGOs rely heavily on individual expertise and educational programs to influence policy and behavior. ${ }^{52}$ Education is of particular importance to the operation of the security coalition. Educational programs and the use of experts to support the propagation of

\footnotetext{
${ }^{49}$ Finnemore and Sikkink 1998 p.898

${ }^{50}$ Ibid p.895

${ }^{51}$ Snow, David A., R. Burke Rochford, Jr., Steven K. Worden, and Robert D. Benford. 1986. "Frame Alignment Processes, Micromobilization, and Movement Participation.” American Sociological Review 51: 464-481.p464

${ }^{52}$ Finnemore and Sikkink 1998 p899
} 
norms nationally and internationally. In this sense, education is used to socialize participants to the new way of behaving. Perhaps the best observable instances of this function of NGOs is among international advocacy organizations. In particular, consider Greenpeace and Amnesty International. Greenpeace USA recently launched their "how clean is your cloud" campaign, an effort to influence Apple, Microsoft, and Amazon to advance their use of clean energy to support the operations of their data clouds. ${ }^{53}$ This particular campaign is part of a broader Greenpeace campaign for renewable energy, an advocacy operation that, along with other similar organizations, has successfully influenced the framing of the energy debate, and to that end, the norms of behavior for a substantial portion of society. Amnesty International maintains offices in more than 80 countries and works to promote the respect of human rights as a norm of behavior. ${ }^{54}$ Much of their work is done through advocacy programs and digital campaigning. Amnesty International is a product of one of the most successful contemporary framing efforts; the categorization of certain rights as "fundamental," "unalienable," or "human", frames certain behavior negatively and has thereby produced a new canon, both international and domestic (the most obvious being the International Declaration of Human Rights). Through their educational activities, Amnesty International extends and reinforces human rights norms.

Education can also have the opposite effect. It stands to reason that if the dissemination of information can bolster the creation of a norm, it can also present a hindrance. Finnemore and Sikkink specifically reference national government and IGO training programs which resist spreading norms. Resistance is not necessarily explicit; that is, the spreading norm is not identified specifically. Instead, resistance is a product of competing ideologies, behaviors, or frames of reference.

\footnotetext{
${ }^{53}$ Greenpeace USA. <http://www.greenpeace.org/usa/en/> last accessed April 18, 2012

${ }^{54}$ Amnesty International. <http://www.amnesty.org/en/who-we-are> Last accessed April 18, 2012
} 
Finally, emerging norms are sometimes supported by institutionalization. Recall I suggested that norms should be thought of as distinct from laws. While this is the case for truly ubiquitous norms, an important strategy in norm propagation is the use of laws to reframe and standardize a given set of behaviors. For a domestic example of this strategy, consider President Lincoln's Emancipation Proclamation, or later, the order by Federal Judge Robert Mehrige in 1971 to begin busing students as an anti-segregation measure. ${ }^{55}$ Both of these cases exemplify the use of legal authority to lend enhanced legitimacy to an issue and enforce an already expanding norm. As for international law, perhaps the best examples come from arms control regimes. In a particularly poignant example from Finnemore and Sikkink, the institutionalization of the prohibitions on the use of chemical weapons, in the form of the CWC, helped gain support for sanctions against Iraq during the First Gulf War.

Around this point in the "lifecycle" of a norm, when the number of adherents has grown significantly enough from the initiating entrepreneur, the norm approaches a tipping point. For Finnemore and Sikkink, the tipping point is the division between stage one and the cascade of stage two. However, in discussing the Middle East, it is necessary to consider realignment as an intermediate step. Also, recognize that while the first stage was discussed in terms of individual interactions and behavior, it is assumed in the transition to the second stage that the emerging norm has taken hold in the originating state (or coalition of states) and through interactions with representatives of other states, is already spreading to neighbors and regional partners. This implies that a tipping point has already been reached on a domestic level in at least one country, and that step two progresses primarily in the spread of norms between governments and social elites, and the conflicts between standing norms and the emerging norm. The Middle East, for a

\footnotetext{
${ }^{55}$ The Virginia Historical Society. "The Civil Rights Movement in Virginia" http://www.vahistorical.org/civilrights/busing.htm last accessed April 18, 2012
} 
number of historical reasons, is a nexus of both competing norms, and competing effects or interpretations of norms, both between states and between segments of civil society. The former of the two conditions is most famously exemplified by the regional unrest surrounding the Camp David Accords and the official peace treaty between Egypt and Israel enacted the following year. In this instance, the Egyptian government was in a state of transition between two competing norms. The dominant regional norm at the time with regard to diplomatic behavior was decidedly anti-Israeli among Arab states. The competing extra-regional norm, to which the primary adherents were the United States and Western Europe, was supportive in their relations with Israel. In this case, norm realignment was isolated in Egypt, but it had the regional effect of upsetting the balance of power, or more appropriately prestige, among Arab States.

Here is where my model diverges from the traditional canon of norms research in political science and international relations. In analyzing the norm lifecycle, there ought to be two distinct levels of engagement under consideration. First is the traditional approach which explains the creation of international norms in terms of government reactions to changing state interests and regional dynamics. The second level, which is more important to the discussion of the Middle East, is the spread of norms through international civil society, and the effect of that spread on government behavior as civil society and governments collaborate on regional issues. In many cases, the civil society component may be negligible. However, cases in which state norms as embodied by government behavior are well entrenched in a given region, the behavior and flexibility of civil society must be considered. As a norm gains domestic momentum, in certain cases the transition of a norm from a domestic to an international arena will occur. This will happen first through civil society activities where norm identities will differ between civil society and government. Over time, realignment occurs as the behavior of governments shift to 
overlay with civil society; this is the operating theory upon which the notion of a track-II security coalition is founded.

Few cases exist in which regions have moved from a state of conflict to the establishment of a regional security regime, and none exist in which the transition entails so dramatic a shift in state behaviors as it does in the Middle East. The origin of the idea is the scholarship that evaluates the goals of NGOs operating in the Middle East, and their effectiveness in pursuing their goals. ${ }^{56}$ A common theme in much of this work is the importance of creating new security norms, or depending on the author, a new security culture. Regardless the intent is the same. In none of these publications is there discussion of something akin to the analysis present in the literature concerning norms, so very little attention is given to the process of creating norms. The stated objective in many cases is the creation of a security regime in the region, the purpose of which is to propagate more cooperative security norms. ${ }^{57}$ Although in some cases this approach has been effective, the Middle East requires the reverse because current state behavioral norms are set firmly against a regionally inclusive security regime (i.e. a security regime that includes Israel). The activities of NGOs operating in the Middle East, both regionally based and with extra regional origins, clearly display a willingness in some sectors of civil society to pursue regional relationships and collaborative efforts that are unfathomable among regional governments. This is the foundation for stage two realignment and the transition from a domestic norm to a regional norm.

In discussing stage three, we have transitioned to state-state interactions as the primary area of concern. Although interactions between domestic actors are still an important component

\footnotetext{
${ }^{56}$ Jones 2011; Kaye 2007; Āghā et al.2003

${ }^{57}$ Jones 2011; Kaye 2007; Āghā et al.2003
} 
to norm creation on an international level, it is important to emphasize factors relating specifically to state behavior in norm creation. Finnemore and Sikkink rely heavily on the explanatory power of state prestige in the spread of norms between states. ${ }^{58}$ They theorize that it takes roughly a third of states in a given region before a cascade will be possible. After a "critical mass" of states is achieved, states outside the emerging norm will be inclined to adopt a norm in order to avoid being pushed to the periphery of regional politics. It is important here to recognize the composition of a critical mass will vary depending on the influence of individual states. In the Middle East for instance, Israel, Egypt, and Syria as members of a coalition will carry substantially more influence than Yemen or Qatar. The concept of critical mass leading to a cascade of new norm adherents in the Middle East is further complicated by the issues discussed under stage two. It cannot be assumed that state interests, especially not prestige, will be compelling enough forces to drive a norm towards regional universality. Iran, for example, would not be compelled to adhere to a norm of regional cooperation under the status quo, even if a coalition of cooperative states were already emerging, because opposition to Israel and their allies is a more fruitful source of state prestige in the region. However, if stage two is successful, regional resistance may be significantly enough reduced to reach Finnemore and Sikkink's tipping point.

In discussing the spread of norms among individuals, it is common to frame norm diffusion as a sort of contagion. Besides framing understanding as a pejorative, in the case of international norms, and based on our understanding of state behavior, it is more accurate to think of norm transmission as a deliberative function. ${ }^{59}$ Just as states may be compelled to

\footnotetext{
${ }_{59}^{58}$ Finnemore and Sikkink 1998 p902

${ }^{59}$ Finnemore and Sikkink
} 
adhere to a norm because of certain state interests, states already conforming to a new norm will be inclined to impress upon their neighbors the value of conformity.

The fourth and final stage of norm development is the internalization of the new norm. In this stage the emerging norm becomes a default behavior, a natural recourse that is not disputed. It is at this stage of norm development when a norm becomes difficult to identify, and therefore difficult to study. The behavior engendered by the standard of the norm becomes ubiquitous, and so indistinguishable. In political science, established norms are not of prominent concern because they are not contentious, and are often ignored by popular political debate (instead, norms provide the common ground in political debate, they frame the political reality for discourse). For an analysis of existing norms, the institutionalists of sociology are helpful for their "denaturalizing" of certain existing norms, such as sovereignty, individualism, and certain characteristics of the market. ${ }^{60}$ This particular area of norms research is of less importance to our discussion of the track-II security coalition, because norms are much more contentious and easier to identify in the emerging three stages of the norm lifecycle, and these three stages are the primary concern of the coalition. However, further research in the influence and development of existing social and security norms in the Middle East would be valuable. The research concerns primarily Western states and identifies a significant degree of similarity between states, and ties these similarities to past norm cascades. Understanding similar relationships would be useful.

The four stages of norm development accommodate both spreading norms between individuals and states, where interactions between civil society institutions and governments of different states help to establish the emerging norm. After a norm is established in one or more

\footnotetext{
${ }^{60}$ Finnemore and Sikkink p904; for a psychologist perspective see Alice Hendrickson Eagly and Shelly Chaiken. The Psychology of Attitudes. Fort Worth, TX: Harcourt Brace Jovanovich College, 1993.
} 
states, there are a number of ways to explain the greater diffusion of norms. While prestige is not particularly helpful in the discussion norm universality in the Middle East, there are a number of processes through which the diffusion of norms might occur as part of a deliberate government or civil effort. Jeffery Checkel provides a vision of these mechanisms that overlay well with norm diffusion in the Middle East. ${ }^{61}$ Although Checkel's work referenced here specifically addresses the spread of already established international norms into domestic politics, and does not address the evolution of new norms, his attention to civil society and education in norm diffusion will be important to understand for a track-II security coalition. In Checkel's approach, norms can be both constraining and constitutive; i.e. the values inherent in an established norm may not be adopted by elites, but the broader acceptance of the norm forces some degree of adherence, as opposed to a norm that exists as a shared understanding or identity and constitutes a deeper connection between adherents. Either way a norm is manifest, the process through which a norm enters domestic politics is called "empowerment." This occurs in two possible ways, the first of which is similar to the second stage process of realignment previously described. Checkel articulates a constraining norm that spreads through advocacy by civil-society institutions and their interactions with governments. Elites do not adopt the norm, but their behavior is nonetheless constrained by its proliferation. The second mechanism of norm diffusion is through the occurrence of learning and socialization between interacting elites. Here, norms are learned and internalized in a constitutive process.

\footnotetext{
${ }^{61}$ Jeffery T. Checkel "International Norms and Domestic Politics:: Bridging the Rationalist--Constructivist Divide." European Journal of International Relations 3.4 (1997): 473-95.; Jeffrey T. Checkel. "The Constructivist Turn in International Relations Theory." World Politics 50.2 (1998): 324-48.
} 
Checkel uses a coding process to evaluate the different ways norms spread between states. He applies this approach to some members of the Council of Europe (COE). ${ }^{62}$ Four categorizations of states are used in Checkel's approach: liberal, corporatist, statist, and stateabove-society. For each category, he identifies which actors will be most influential in the diffusion of norms. ${ }^{63}$ In liberal societies the dominant force, and the only one considered, is societal pressure on governing elites. In a corporatist structure, the primary influence is social pressure and a secondary factor is participation from elites. The reverse is true in statist structures, where elite learning is dominant and social pressure is secondary. Lastly, in the authoritarian state-above-society structure, the only factor at work is elite learning. It is worth noting that Checkel deliberately leaves out coercion from his analysis, whereby powerful states pressure their weaker counterparts to adhere to certain behavioral standards. This omission is explained by his intention to present a causal account of norms influencing international politics by synthesizing two previously disparate theoretical perspectives. Because coercion is part of the realist explanation for how norms are perceived and therefore is fundamentally at odds with the existence of norms in international politics, it cannot be usefully incorporated in the same theoretical framework.

Checkel uses the successes of the COE to explain the appropriateness of his categorizations. The COE represents a reasonable catalyst for the subject of norms diffusion for multiple reasons. As an international regime, it consists of a variety of states from each segment of Checkel's spectrum of state organization. Furthermore, among international organizations,

\footnotetext{
${ }^{62}$ Checkel 1997

${ }^{63}$ Checkel 1997 p.478
} 
the COE is considered one of the most effective collaborative bodies. ${ }^{64}$ Finally, as an advocate for the European human rights regime, the COE has proved a successful device for spreading humanitarian norms, specifically citizenship and minority rights. Checkel selected four states for his analysis: Ukraine, Russia, Germany, and Great Britain, which are categorized as state-abovesociety, statist, corporatist, and liberal respectively. The challenge of this sort of analysis is to both prove the existence of a norm, and the absence or contested status of the same norm in the domestic arenas being evaluated. In order to achieve this, Checkel relied both on careful readings of relevant European treaties a series of interviews with bureaucrats and politicians involved in national implementation of the treaties being considered. ${ }^{65}$

Civil society groups operating in Ukraine are predominantly small and almost entirely ignored by the government, hence the importance of elite education for norm diffusion. The successful advance of citizenship rights in Ukraine is explained through the interactions between Ukrainian elites in the 1993 Interdepartmental Commission for Questions of Ukraine's Admission to the Council of Europe. The integration and learning from the admission process enabled the diffusion of norms to the political elite in Ukraine, despite the absence of effective social pressures. Like Ukraine, elite learning in Russia was facilitated by groups of government elites whose responsibility it was to interact with their $\mathrm{COE}$ counterparts. In this case two bodies were established. The first, the 1992 Citizenship Commission, was attached to the President's office, and the second, the Directorate for Pan-European Cooperation, was part of the Foreign Ministry. Although elite education was the primary mechanism of diffusion at work, the Moscow School of Political Studies, although its actions are restricted by the Foreign Ministry, is

\footnotetext{
${ }^{64}$ Checkel 1997; Andrew Moravcsik. "Liberal Intergovernmentalism and Integration: A Rejoinder." JCMS: Journal of Common Market Studies 33.4 (1995): 611-28.

${ }^{65}$ Ibid pp.481-2
} 
part of an extensive network which was able to apply limited societal pressure on the government. In Germany, the empowerment process was much more complicated and involved considerably more civil society participants. The best example of societal pressure came in the form of a petitioning effort, begun in 1992, which gathered over a million signatures. There were also COE forums which helped to propagate citizenship norms among the public. As a secondary influence, Checkel identifies political leaders who became advocates for the new citizenship norms, but whose input was less influential than the petitioning project. Lastly, the liberal structure of Great Britain enables substantial influence to flow from social pressures. In a number of COE-related areas, including citizenship, domestic institutions in Britain have appealed to the European Commission and the Court of Human Rights in order to pressure British government.

Checkel's framework is helpful in organizing one's thoughts about norm diffusion in a given region, but it is lacking in three particular ways. First, the categorization is an artificial process and inherently limits the ability to evaluate differences within categories and confines the understanding of subject states. Although the model appears to fit well with the four European states, it may be less instructive if each category were illustrated with more than a single state. Differences among states within categories shows variances that exist between similarly structured societies and thus presents problems with Checkel's model. Secondly, Checkel's model does not account for changes in state behavior as the diffusion process progresses. The most evident example of this shortcoming in the Middle East is the shift in conditions in Egypt since early 2011. Under the Mubarak government, Egypt would likely be considered state-above-society (although a case could be made for statist as well). Today, shifting power structures make it difficult to decisively say which category Egypt should fall 
into, let alone how particular actors, such as the Military Council, are likely to interact with civil organizations. Admittedly, Checkel's model is clearly designed for retrospective analysis, so shifting conditions and the convolution of current events were not problematic in considering European citizenship norms (although he acknowledges a predictive component to his analysis of the diffusion to Great Britain). ${ }^{66}$ Finally, the four categories, each with varying degrees of social pressure and elite learning acting as the mechanisms of diffusion, does not account for external pressures from foreign governments or civil institutions. To the extent that foreign actors are considered, it is as part of the learning process of elites, whereby norms are internalized. In the Middle East is necessary to consider the influence of state and civil society pressures from outside the domestic arena. For instance, the decision-making calculus for Lebanon will vary between instances in which it is acting with relative independence, and when it is acting as part of a coalition of regional partners. The analysis of citizenship advocacy in Britain included discussion of external pressure, but this should not be isolated in the Liberal category of state organization.

Like Checkel, I do not believe it is useful, let alone accurate, to disallow the simultaneous consideration of both constitutive and constraining theories of norm diffusion, operating on differing levels and between different institutions, but within the same society. Depending on the actors and circumstances, either process may be extant. However, I move a step further by allowing for both constitutive and constraining effects in either of the two diffusion processes, because in some ways the distinction between the two is artificial. I propose, as part of the realignment process, that norms will be learned by government elites not only by interacting with other government elites, but through the instruction, example, and cooperation with civil society

${ }^{66}$ Checkel 1997 p487 
institutions. Through this unified process, it seems inevitable that some portion of elites will fully internalize the norm, whereas others, influenced both by civil society and their foreign and domestic elite counterparts, will be constrained.

The role of track two projects, as envisioned in this paper, is to enable the process of norm diffusion. By creating previously nonexistent links within and between communities in the Middle East, the track II coalition would stand to move regional integration, and the prerequisite peace negotiations and disarmament treaties, further than regional precedent. Although the early stages of creating the coalition are a concrete, short-term option for advancing Middle East relations, it must be understood that norm diffusion, as a catalyst for improved relations, may take many years. With this broad view of norm diffusion, it is now necessary to narrow our focus to a consideration of half the norm diffusion equation; the relationship between publics and their governments.

\section{Public Opinion, Education, and Security Policy}

In providing a review and analysis of public opinion literature, this section serves two important purposes. To begin, a better understanding of public opinion helps to elucidate the process of norm diffusion between a given public and their government. In the terms presented in this section, this process is primarily embodied by the various means of public expression, and how opinion can be measured, evaluated, and presented to governors. Additionally, and more practically, the presented literature (and accompanying critique) helps to explain how a track two coalition can work to avoid the sort of media backlash and public opposition which has dashed many previous projects. This process is the reverse of the former, in that it outlines how track II 
projects can undertake educational and public engagement programs to help create media diversity and ideally, a better informed public.

Recalling the review of NGO projects in the Middle East, and the importance of interacting effectively with the public during the filtering process, the following section analyzes perspectives on the interaction between public opinion and security policy. Most of the work in this field uses data based on voting records, polling, and corresponding relationship to policy implementation. Nearly all of this work uses data from the United States, and much of it concerns public opinion about either the advancement or elimination of nuclear weapons. Although the contributors to this field are many, the limited scope of the existing research presents some problems as we turn towards the Middle East. The most immediate concern is the lack of accurate polling in the Middle East on foreign policy and security issues. In the absence of this sort of data it is difficult to reasonably translate the lessons of Western studies to the existing circumstances in the Middle East (reminiscent of the problems faced by Checkel in his COE case study). Therefore, much of this section will address broader theories of social influence and synthesize a basic theoretical framework for considering the role of public opinion in the Middle East.

Over the last century, two schools of thought have emerged in the study of how public opinion influences the state: the traditionalists and the revisionists. The former generally believing the public to be incapable of developing accurate opinions on security and foreign policy issues, whereas the latter presents a variety of perspectives explaining how the public can, under certain conditions, make positive contributions to foreign policy. In 1925, Walter Lippmann published one of the first and most widely known traditionalist perspectives, in which 
he famously referred to political leadership being "trampled by the bewildered herd."67

Following Lippmann came a long line of scholarship, although many of the most notable traditionalists did not come to fore until the 1950s and 1960s. ${ }^{68}$ In their analysis of the field, Hank Jenkins-Smith and Kerry Herron identify three traits of the traditionalist perspective. First, mass publics generally lack the sophistication and educational background to contribute to policy discussions that involve complex ideological perspectives and technical comprehension. Second, traditionalists rely on empirical evidence suggesting that average citizens lack belief systems that can produce useful opinions in the absence of sufficient knowledge. Finally, the mass public lacks the means to analyze and understand complex issues. Herron and Jenkins-Smith characterize the adherents to traditionalism as "political sophisticates, theorists, and academics" who came to guide the generally accepted understanding of public opinion.

To represent the traditionalist perspective, I use the 1956 analysis from Gabriel Almond, and the 1968 work by James Rosenau. Almond begins by dividing society into five components: government, media, interest groups, the attentive public, and the mass public. The nature of the division between publics is our foremost concern. With regard to the mass public, Almond points out that the development of security policy, by its nature, is a secretive process. The limits placed on information diffusion in security policy prevent the mass public from developing accurate opinions. Furthermore, Almond supposed that the stakes in discussions of security policy, as opposed to domestic policy, are often so great and abstract to the average member of the mass public that they become effectively meaningless. The primary means of obtaining information in the mass public is from the mass media, which is itself subject to

\footnotetext{
${ }^{67}$ Walter Lippmann. Public Opinion. New York, Harcourt, Brace and Co. 1922

${ }^{68}$ Gabriel Almond. "Public Opinion and National Security Policy" Public Opinion Quarterly, Summer 1956, vol. 20, no. 2, p. 371-378; James N. Rosenau. National Leadership and Foreign Policy; a Case Study in the Mobilization of Public Support. Princeton, NJ: Princeton UP, 1963; James N. Rosenau. Public Opinion and Foreign Policy; an Operational Formulation. New York: Random House, 1961.
} 
skewed and incomplete information. In the absence of knowledge, Almond suggested that the mass public responds in "moods" to the stories they are exposed to through the media. Rather than using the media to form an accurate, informed opinion, the mass public uses media inputs to decide how they ought to feel on a given issue. The central notion in dividing the capacities of the two publics to engage in policy could be thought of as information asymmetry; this is the common thread running through traditionalist theories of public opinion. The ignorance and irrational tendencies of the mass public are balanced somewhat by the much smaller, but still influential, attentive public. The composition of the attentive public falls somewhere between policymakers, academics, influential elites, and the mass public. These are the members of society who make it their business to be informed about security policy. They form reasoned opinions and provide a stabilizing force in the arena of public discourse.

In a transition spanning the last three or four decades, the traditionalists have largely been replaced by revisionist theories. The guiding principles of the traditionalist paradigm were increasingly viewed as prohibitively pessimistic concerning the cognitive competency of the general public. Among the most compelling early revisionist publications came in the 1970s and called into question the methodology of the prominent traditionalist scholars. ${ }^{69}$ These early critiques focused primarily on the structure and implementation of survey projects used to portray the mass public as ignorant and capricious. A common flaw in these surveys was a failure to recognize and minimize instances of question bias. The emphasis of the traditionalist perspective on the acquisition of raw information in the decision making process, resulted in a heavy emphasis on survey questions requiring subject-specific knowledge. In the revisionist

\footnotetext{
${ }^{69}$ William R. Caspary. "The 'Mood Theory': A Study of Public Opinion and Foreign Policy."American Political Science Review 64.2 (1970): 536-47; Christopher H. Achen "Mass Political Attitudes and the Survey Response." American Political Science Review 69.4 (1975): 1218-31.
} 
view, the absence of advanced academic work or policy experience in the security field should not be considered prerequisite to the formation of relevant opinion amongst the general public. Two prominent publications in the 1980s advanced the revisionist claim that although survey data can be interpreted to show a divide between the opinions of the mass public and elites, the conclusion should not be that the mass public is incorrect. ${ }^{70}$ A more recent study from the Chicago Council on Foreign Relations (CCFR) reinforced the conclusions of earlier works with a data set spanning nearly a decade. The CCFR publication acknowledges gaps between public opinion and elites, but where traditionalist literature attributes these gaps to the ignorance of the public and the comparative wisdom of elites, the gaps are now explained by analyzing disparities between the values, goals, and interests of the two groups. ${ }^{71}$

The most important facet to the revisionist perspective is the understanding that members of the public need not have all the facts on a given policy in order to have a relevant opinion. ${ }^{72}$ Although a certain amount of information is necessary to make an informed decision, Lupia and McCubbins present an analysis that highlights the ability of individuals to discern which information is most useful when it is presented to them. They place value on the ability to ignore or forget information. Rather than being able articulate a thoughtful opinion on the more nuanced aspects of security policy, it is more important that a member of the public be able to understand the likely consequences of a policy as they apply to their interests. By distinguishing between the sort of decision burden elites face, and the lesser burden of the public, it becomes

\footnotetext{
${ }^{70}$ Robert W. Oldendick, and Barbara Ann Bardes. "Mass and Elite Foreign Policy Opinions."Public Opinion Quarterly 46.3 (1982): 368-82; Eugene R. Wittkopf. Faces of Internationalism: Public Opinion and American Foreign Policy. Durham: Duke UP, 1990.

${ }^{71}$ Benjamin I. Page and Jason Barabas. "Foreign Policy Gaps between Citizens and Leaders."International Studies Quarterly 44.3 (2000): 339-64.

${ }^{72}$ Arthur Lupia and Mathew D. McCubbins. The Democratic Dilemma: Can Citizens Learn What They Need to Know? Cambridge, U.K.: Cambridge UP, 1998; Yankelovich, Daniel. Coming to Public Judgment: Making Democracy Work in a Complex World. Syracuse, NY: Syracuse UP, 1991.
} 
less important that the two groups demonstrate equal subject knowledge. Extending upon these differing standards, it is helpful to consider James Surowiecki's work on collective judgments, and his four part characterization of a "wise" public. ${ }^{73}$ First is information diversity, which requires that public beliefs be grounded in at least some fundamental understanding of all relevant issue factors, including a basic technical understanding. The second category, independence, requires that individuals are not pressured to conform to a particular belief. Third, decentralization requires that individuals be able to consider local and personal experiences. Finally, aggregation accounts for the importance of being able to synthesize policies or collective decisions using the assorted individual judgments. Surowiecki's analysis is more restrictive than most revisionists, indeed its emphasis on information diversity seems to draw from the traditionalist perspective, but the purpose of the four categories is different from most revisionist projects. In Surowiecki's text the four categories are discussed in terms of "correctness" rather than simply appropriateness or legitimacy as you might find in similar publications. The four categories describe the conditions that must be met in order for the mass public to produce an actionable policy, whereas revisionists like Page and Barabas from the CCFR project focused on the ability of individuals to make judgments based on their own distinct values and goals, rather than those of the state more generally.

In their 2006 publication, Herron and Jenkins-Smith provide a summary of the five axioms of revisionist theory. The first axiom is a point we have already discussed; a complete knowledge set is not a prerequisite for making valuable policy choices. Belief systems (such as liberalism, realism, or rationalism) serve to both support and constrain mass publics in the same way elite discourse relies on them to provide coherence and consistency, but a nuanced

\footnotetext{
${ }^{73}$ James Surowiecki. The Wisdom of Crowds: Why the Many Are Smarter than the Few and How Collective Wisdom Shapes Business, Economies, Societies, and Nations. New York: Doubleday, 2004.
} 
understanding of them is not required. Short term variances in mass opinion should not be taken as changes in preferences because long-term data shows a greater degree of consistency. In the short run, while members of the mass public may use belief systems and heuristics adopted from elite policy debates, data shows that over the long run public beliefs influence government behavior. Finally, although it can be demonstrated that the mass public relies heavily on personal values, goals, and interests, it should not be assumed that the public is incapable of appreciating certain general public interests. Although this system of axioms is drawn from studies using mostly the American public, many of the general conclusions can be applied to our study of the Middle East, and will inform to the structure and operations of a track-II coalition articulated in the following section. In making the shift towards the Middle East, the most helpful analysis of public opinion is provided by Daniel Yankelovick. ${ }^{74}$

Yankelovick’s revisionist perspective concerns democratic publics, but provides a useful means of distinguishing between "good" and "bad" public judgments. Yankelovick first provides a definition for "quality," which provides a basis for distinguishing between good and bad. The quality of public opinion is good "when the public accepts responsibility for the consequences of its views" and it is bad "when the public, for whatever reason, is unprepared to do so."75 Two additional defining characteristics include the firmness with which an individual adheres to a judgment, and the degree to which a given judgment contradicts the values expressed by judgments in related issue areas. ${ }^{76}$ The value of Yankelovick's approach is in placing the quality determiner on what an individual does with the knowledge they possess, rather than how much knowledge they possess. Even among revisionists, few have done this so

\footnotetext{
${ }^{74}$ Yankelovich 1991

75 Ibid p24

${ }^{76}$ Ibid p31
} 
effectively as Yankelovick. The driving forces behind this approach are observations in which the expression of public opinion has failed to account for likely consequences. Two of the examples from Yankelovick's text are especially useful. In a 1986 news poll, 65 percent of respondents said they were in favor of a constitutional amendment that would require Congress to balance the budget annually. When later questions included the stipulation that balancing the budget would likely require increased federal taxes, favorability dropped to 39 percent. In another example, specifically related to security policy, Yankelovick reviews public sentiments directly following the taking of US hostages by Ayatollah Khomeini in 1979. The vehemence with which some members of the public responded, using phrases like "nuke 'em," was an instance of bad public judgment. In a third example, from Herron and Jenkins-Smith in their analysis of public opinion and the maintenance of the U.S. nuclear arsenal, we again see the consideration of repercussions in polling data. When polled, 53 percent of American's voiced support for expanding the size and ensuring the technical superiority of the existing nuclear arsenal. However, when it was included that such an expansion would require additional nuclear testing, the percentage in favor dropped to 41 percent. ${ }^{77}$ Each of these examples illustrate Yankelovich's framework for distinguishing between qualities of public expression.

The two examples using polling data above are helpful in considering Yankelovich's maturation process of public opinion, which is furthermore a helpful explanation of the sometimes erratic behavior of the public. While other revisionists typically rely on a critique of survey methodologies to explain the traditionalist understanding of the capricious public, Yankelovich introduces three stages of public opinion development. First is the consciousness raising stage, in which a policy is introduced to the public arena. Second is the working through

\footnotetext{
${ }^{77}$ Kerry G. Herron and Hank C. Jenkins-Smith. Critical Masses and Critical Choices: Evolving Public Opinion on Nuclear Weapons, Terrorism, and Security. Pittsburgh, PA: University of Pittsburgh, 2006.
} 
stage. As its name suggests, this describes the time when the public is considering how to judge a particular policy or circumstance and how it fits with their existing beliefs. Finally, in the resolution stage, the public settles on a particular set of interpretations and judgments. At this point the public is able to produce "good" public judgments. ${ }^{78}$

Although Yankelovich largely dismisses the relevance of ideology and culture by emphasizing the public's understanding of ends, one of the prominent critiques of his work, there is still room to consider the important inputs that might inform how policy ends are evaluated by the public. Perhaps the most fundamental and influential input is the individual's perception of their demographic status, allowing them to evaluate how a policy will affect their life. ${ }^{79}$ Also fundamental to the individual's perceptions are their political beliefs as informed by ideology. As mentioned above, Yankelovich attempts to remove ideology entirely, taking the position that judgments heavily informed by ideology distort the logical consideration of repercussions. This idealistic account of public opinion denies the possibility of subjective divergence from a judgment that is assumed in Yankelovich's assessment to be objectively good. Although Yankelovich's approach is the most useful under most conditions, we must accept that circumstances exist in which ideology plays an important role in making policy judgments, and that it is right for it do so ${ }^{80}$ Similar to the core beliefs encompassed by ideology, "domain perceptions" are perspectives that apply to a particular area of policy. ${ }^{81}$ Lastly, as a subdivision of domain perceptions are beliefs specific to individual policies. ${ }^{82}$

\footnotetext{
${ }^{78}$ Yankelovich 1991 pp63-5

${ }^{79}$ Herron and Jenkins-Smith 2006

${ }^{80}$ Ibid p6

${ }^{81}$ J.T. Ripberher, T.M. Rabovsky, and K.G. Herron. "Public Opinion and Nuclear Zero: A Domestic Constraint on Ditching the Bomb." Politics and Policy 39.6 (2011): 891-923.

${ }^{82}$ Ibid; Herron and Jenkins-Smith 2006
} 
A more difficult question to answer than how public opinion is formed is how public opinion comes to inform policymaking. As with the preponderance of literature on the subject, most analyses rely on American polling data and election records, or those from other Western, liberal democracies. It is my objective here to provide both a useful perspective on comparing democratic governing structures with undemocratic structures with regard to public influence on policy, and then to describe the range of activities accessible to various publics in their interaction with policymaking elites.

The common understanding of public-government interaction in liberal societies emphasizes the importance of the democratic process. However, when public opinion development and communication is broken down into its component parts, the process of electing government representation is at best secondary to the role of lobbying and other activist projects coordinated by NGOs. Rather than thinking of government liberalism in terms of elections, it is a more accurate reflection of the liberal policymaking apparatus to think in terms of the degree to which the public can engage in policy dialogue and apply social pressure. While impending elections will make elected officials more sensitive to public pressure, the role of regular elections is similar in effect to an active protest culture in undemocratic systems, although the latter is less consistent. It is also worth noting that the culture-producing effect of public engagement in policymaking through track-II programs is both similar to, and may be a precursor to, the culture-production of elections. Understanding the relationship between public opinion and policy makers in these terms allows us to draw more useful comparisons between the research done in liberal societies, and the future of Middle Eastern politics. In other words, where political cultures and governing systems operate differently, parallels may exist between 
publics and how individuals formulate their opinions, and the means through which they influence their respective governments.

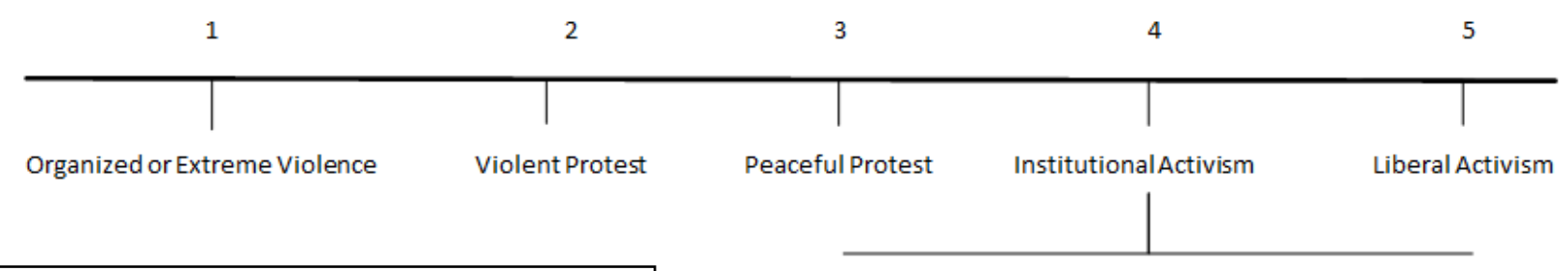

Figure 4: The scale presents a variety of means for Activism by Select Elites

RepresentativeActivism public expression, ranging from most extreme on the left, to the most liberal on the right. Although activities on the left can be present in varying degrees of liberal and authoritarian societies, note that those on the right are only accessible in liberal societies.

In order to better evaluate the interaction between publics and governments, I have identified a range of five activities in the realm of public expression, as portrayed in figure 4 . The first level, furthest to the left of the diagram, includes only the most violent activities, often with malicious intentions, which accounts for everything from outright revolt, to vandalism, to insurgency. This level of analysis includes only the most extreme cases of violent public expression. The second level is violent protest. The line between revolt and violent protest is fine, and the former may evolve into the latter. The third level is peaceful protest. For example, consider the Egyptian protests during the winter of 2010. While there were violent acts perpetrated by some members of these protests, the movement as a hole was peaceful and was not characterized by violent conflict with the entrenched authority. I refer to the fourth level as "institutional activism." Public engagement efforts in this category are lead and facilitated by NGOs. In the earlier review of NGO activities in the Middle East, many of the projects listed would fall into this category. However, it is important to recognize that within this category there are varying degrees of interaction between the NGO managers and the public they 
represent, hence the subdivision of the category between activism by elites, and representative activism. As contact with the public increases, the activity moves nearer to the fifth level, broadly identified as "liberal activism." These sorts of activities include examples such as petition projects and letter-writing campaigns. Liberal activism entails a high degree of individual autonomy and freedom of political expression.

In considering NGO projects in the Middle East, the most important goal should be to broaden public accessibility to more levels along the spectrum, while diminishing reliance on those forms of public expression furthest to the left. Note that protest is generally a healthy political activity, and the maintenance of a protest culture in the Middle East need not be to the exclusion of more liberal forms of political expression. Broadening the means of public expression will increase the legitimacy of public opinion, and eventually facilitate a healthy relationship between the mass public and government, with the NGO community as an intermediary. Under the status quo, one of the greatest struggles faced by NGOs is the communication of their goals and activities to the mass public. This failure becomes problematic when in cases such as the Search for Common Ground project in 1993, where media and mass public reactions brought about the collapse of an otherwise promising policy dialogue. If a coalition of NGOs is going to be any more successful than the existing dispersal of independent NGO projects, it must improve public relations across the region. Even moderate success in this endeavor will provide an improved public foundation for regional reconciliation and cooperation than exists today. 


\section{Part III: The Goals, Structure, and Encumbrances of a Track-II Coalition}

\section{Track II v. Track I}

In beginning the discussion of a possible track II coalition, addressing its participants, goals, and structure, it is helpful to outline why the unofficial option is more favorable at this juncture than the more commonly proposed official approaches. To start, in the existing scholarship on the subject, some of the most notable authors have suggested that further track II activities could be beneficial in the development of positive security relations in the region. ${ }^{83}$ In fact, Spiegel opened a recent publication on Middle East security by acknowledging that track II projects may be the most appropriate option for the international community given the current regional climate. ${ }^{84} \mathrm{He}$ later recognizes that it may be necessary to "develop an informal, even at times unofficial, structure to maintain ongoing discussions, build confidence, and at a minimum discuss disagreements. ${ }^{\circledR 85}$ Unfortunately, neither Spiegel nor Jones provides more than a sentence or two on the subject, and to the extent they clarify their track II recommendations, the emphasis is functionally the same as their track I proposals. They do not avail themselves of the flexibility, influence, and public engagement which can be achieved through an unofficial effort.

The most important advantage in pursuing a track II solution as compared to an official regime is the ability to cultivate security and diplomatic norms. Much of the literature on Middle East security finds that the creation of a security regime, with a robust network of CSBM, will propagate norms between regional governments. Comparisons to precedent-setting regimes in other regions, such as ASEAN, support this conclusion. However, the second half of the twentieth century and first decade of the twenty-first have time and again showed an

\footnotetext{
${ }^{83}$ Jones 2011; Spiegel 2004

${ }_{85}^{84}$ Spiegel 2004 p75

${ }^{85}$ Ibid p85
} 
unwillingness amongst regional governments to settle on the terms of an inclusive regional organization. The issues network in the Middle East is such that too many competing interests have prevented the development of consensus to the extent required for the first steps in creating a regime. Fortunately, NGOs do not have the same restrictions on who they partner with. The potential risks of participating in an unofficial coalition are rarely prohibitive, and in many cases, participation would be complimentary to the collective missions of the various NGOs. For example, a partnership between The Search for Common Ground and the Cooperative Monitoring Center would combine their respective expertise in political resolution and defense policy to better facilitate dialogue on security issues. Through the success of NGO partnerships, there is an increased likelihood that a new political culture could emerge among political elites. This development would better prepare the region for the establishment of an official security regime. Without the track II coalition, academics and policy analysts can only sit and hope that political conditions shift in favor of their regime designs.

Political and economic conditions, as one of the greatest barriers to the creation of a security regime, would likely require reform before an official regime could take hold. ${ }^{86}$ In most proposals, and for most international precedents, these reforms are agreed upon by member countries prior to formally becoming members to the regime. As states meet these agreed upon requirements by the founding states they become eligible for entry. An unofficial coalition provides a forum for pursuing these reforms and building consensus around appropriate standards. Not only does the track II approach provide a forum for developing reforms to create a foundation for a security regime, but NGOs by their nature are better positioned to work with public interests, such as a growing business community that would support economic and

\footnotetext{
${ }^{86}$ Spiegel 2004
} 
political reformation. Spiegel points out that the expanding regional business community, emerging just in the last few decades, has increasingly favored reconciliation in the region because they want better access to regional and global markets. An unofficial coalition could work with these interests to mutual advantage, while for these private entities it would be more difficult to interact with an official regime.

Perhaps the most obvious advantage of an unofficial coalition is the irrelevance of the prohibitive concerns felt by governments entering into international arrangements. The three barriers to the creation of a security regime identified earlier, political and economic stability, and the potential for balance of power rivalries, have no bearing on NGOs. In addition to these three broad scale barriers, progress in the Middle East is often slowed by the competition of issues. Recall for instance the earlier discussion of the ACRS process, which while at first appearing promising, was eventually derailed by an overemphasis on Israel and Palestine lead by Egyptian representatives. The bureaucratic slowness inherent in any official international organization renders efforts open to this sort of failure. While it stands to reason that NGOs will be likely to collaborate because of their overlapping missions, they will maintain a great degree of independence within the coalition. The flexibility of an unofficial organization will allow the coalition to undertake, as they already do, a variety of issues simultaneously between different groupings of coalition members and different focus states. The failure to resolve one issue will not cripple ongoing efforts with different issues, while progress in one area could still potentially benefit another. As issues are resolved in this piecemeal fashion, the barriers preventing states from entering a new regime under the status quo would gradually be reduced. The easing of 
tensions in this manner will open the way for the pressure of overlapping strategic interests and domestic and public pressures to move the region towards a sustainable official regime. ${ }^{87}$

\section{Goals}

The overarching goal of a track II coalition in the Middle East is to establish a regional network capable of providing a foundation for the development of an official security regime. This process would occur in three stages. The first stage is of course the establishment of the NGO network. Building from the successes of an integrated NGO community, it will eventually be possible to establish a security forum for regional governments. This would be a centralized institution acknowledged by as many states as possible as a forum for the resolution of disputes. The final stage will be the establishment of a centrally organized institution that will eventually resemble the institutional structure of ASEAN. This organization could develop subordinate working groups for each region, a regional court for adjudicating disputes, and an assortment of offices responsible for specific policy areas. Recall the four categories of regimes introduced in the beginning of Part II: legal, restrictive, cooperative, and allied. When considering the coalition itself, it would obviously fall outside any of the categories presented earlier and represents the least-integrated form of regime possible. As the coalition evolves it will gradually increase participants, both NGOs and governments. The first step beyond a track-II coalition will likely be a legal regime having to do with either environmental or economic policy. Success in later stages of regime development will the success of existing efforts on more contentious policies, such as those undertaken by CWCC to promote the universality of the Chemical

${ }^{87}$ For a description of overlapping strategic interests see Kenneth N. Waltz. Theory of International Politics (New York: McGraw-Hill 1979); Spiegel 2004 
Weapons Convention. With regionally inclusive CSBMs as a foundation, the creation of a restrictive or cooperative regime will become increasingly likely.

The primary force at work in the progression between the three stages is the diffusion of norms. Recall the discussion of the norm "lifecycle" from Finnemore and Sikkink. This understanding of norm development moves between norm emergence, realignment, norm cascade, and internalization. The activities sponsored by the members of the track-II coalition are the points of emergence for the new diplomatic and security norms which will provide a foundation for improved regional relations in the long-run. As norms spread between publics and elites, the process of realignment will occur in which government interests and behaviors shift to reflect the spreading norms. In this sense, realignment would occur so that state interests overlay with projects facilitated by the coalition and treaties that have successfully implemented treaties. Facilitating realignment, as a component of norm diffusion, is one of the central functions of the coalition. Following the potentially lengthy realignment process, a norm cascade will occur among newly aligned governments, after which, the broad internalization of norms will create an environment conducive to the creation of a robust and inclusive security regime.

As discussed in the section addressing security norms, norm diffusion can be supported through civil society interactions with governments, publics, and other civil society institutions. The primary operating goal that should dictate both the types of projects the coalition undertakes and the manner in which they pursue them is the diffusion of favorable norms and the development of a healthy regional political culture. Diplomatic and security norms will diffuse through elite interactions and public engagement (recall figure three) and in some instances be codified in bilateral and multilateral agreements. These activities are considered CSBMs under 
the definition from Intriligator, introduced in Part II. Under this understanding of CSBMs, it is worthwhile to promote not only military engagement, but also political and economic engagement in the form of bilateral or multilateral partnerships on issues of shared importance. For example, some members of the coalition could work to engage regional partners in dialogue concerning possible solutions to the annual water shortages faced across the region.

Environmental policy is not often included in a list of potentially fruitful CSBMs, however, as a shared regional concern, if effectively integrated into a regional approach, environmental policy stands to provide a catalyst for norm diffusion that is as effective as traditional alternatives.

The development of new policies through cooperation between coalition partners and between governments should, of course, be a part of the coalition's operating plan, but it should not be the primary goal. These policy discussions should be thought of as a catalyst for developing cooperative relationships, regardless of the outcome of specific dialogues. Most importantly, the success and failure of the coalition should not be judged based solely on the number of successful policies its projects produce (although successful policies will be an indicator that the broader goal of norm diffusion is progressing). If track II projects result in new policies, it should be thought of as a positive byproduct of the coalition's operation.

A final goal of the coalition is to improve the quality of public opinion. This goal is central to the public engagement mission of the coalition. Recall Yankelovich's emphasis on an appropriate consideration of ends in the formation of "good" public judgments. Yankelovich provides a framework for determining the validity of an opinion, where the practical implications of his perspective require improved educational programs to more effectively and accurately convey policy. By engaging in educational programs the coalition will work to improve the quality of public opinion among mass publics, informed publics, and elites. Like each of the 
goals described in this section, this is an enormous undertaking that will require a great deal of time and collaboration within a broadly inclusive coalition.

\section{Structure and Function}

In this section it is helpful to recall Almond's five components of society described at the end of Part II in the public opinion section: government, media, interest groups, the attentive public, the mass public. It is also helpful to recall figure two, which presents a visualization of the interactions between the five components and the coalition.

To begin the description of the coalition's operating structure, we must consider the participants. The NGOs and projects reviewed in the first section are representative of the types of organizations that would make up the composition of the coalition. It is important to have a diversity of institutions participating in order to maximize the effectiveness of the coalition as a whole. Participants should include independent research centers, universities, businesses, think tanks, advocacy groups, and monitoring centers. Although a significant majority of these groups ought to be based in the Middle East, it will be appropriate to involve international groups in order to access the breadth of expertise available in the international NGO community. Participants should not be limited to organizations with security-related missions. The variety of policy issues peripherally relevant to security policy in the Middle East requires a depth and breadth of specialties be incorporated in the coalition. The Institute on Global Conflict and Cooperation, the AAAS, the CWCC, SIPRI, the Search for Common Ground, and the Cooperative Monitoring Center focus primarily on security issues, but from differing approaches. The AAAS supports projects designed to build relationships in the scientific 
community. The Cooperative Monitoring Center trains military and political leadership in verification measures and technology supporting arms control treaties and an array of CSBM. The Search for Common Ground focuses its work on supporting negotiations between governments and building political relationships. An expanded coalition would build on this foundation with organizations facilitating government-business relationships in the region and policy-specific organizations (refugees, resource scarcity, etc.). Finally, the membership of the coalition must be drawn from as many states as possible, without too heavy a concentration in any one place. It will be necessary to include participants from important peripheral states as well, such as Iran, Turkey, and possibly Pakistan and Afghanistan. This will be the most challenging consideration in building the coalition.

It is unreasonable to expect upwards of one hundred private institutions to participate in a collaborative organization from the start, so the coalition will grow in stages, as described earlier in the Goals section. This gradual process of increasing regional inclusivity will likely resemble something similar to the process undertaken by the CWCC, where with each event sponsored by the coalition they draw a larger assembly and increase their membership. The most important first step is to establish a core assembly of participants from the region. Ideally this would include participants from nearly all states in the region, but at least the key states: Israel, Syria, Egypt, and Iran. These four states are typically identified as the key components to any sustainable regional solution. The omission of any one of them would undermine the integrity of the coalition, and from a track II perspective it will be necessary to have NGOs based in these countries in order to facilitate cooperation with the government on policy issues and the eventual creation of an official regime. This early group of NGOs would establish the guiding principles for the coalition, the organizational structure, and a plan for growth and development. The 
guiding principles of this organization must not explicitly exclude any governments or NGOs from participating in coalition projects. From this foundation, the coalition will gradually extend its membership to include more political ideologies and economic sectors in more countries. In order to maintain representational balance across the region, it may be appropriate to restrict the number of participants allowed to join from a single country by creating a ratio quota. For example, it may be acceptable for three Israeli participants and one Saudi Arabian participant to enter at the start, but before a fourth Israeli institution can enter the coalition, there must be increased representation from Saudi Arabia. Alternatively, these quotas could be organized by region. This approach would encourage sub-networks of NGOs from across the Middle East to collaborate and join the coalition at the same time, in order to maintain balanced representation. These specifics for managing growth would be articulated in the coalition's guiding principles.

I divide the rest of the discussion of the structure and function of the coalition into two components reflecting the structure of the issues presented in this paper. First is the function of the coalition as a norm-diffusion apparatus. The coalition will create an environment to collaborate and discuss. The projects undertaken by the coalition will be similar in structure to those reviewed earlier, and will involve dialogue between NGOs, between governments, and even between different departments of the same government. One of the strengths of the coalition will be the ability to track participants in various projects and to build on the successes of previous projects. Under the status quo, NGO projects primarily occur in isolation, so when they conclude or collapse, it is difficult to salvage the areas of the project in which progress was made. For an example of where this sort of engagement would be beneficial, consider the bureaucratic cultures of the Egyptian Foreign Ministry and the Israeli Defense Ministry as expressed in the ACRS proceedings. By their behavior, it is clear the Egyptian Foreign Ministry 
is inclined to adhere more nearly to international diplomatic and security norms, whereas the Israeli Defense Ministry favors "uncompromising self-reliance." ${ }^{88}$ Further complicating matters, in the process of establishing the guiding principles in the ACRS process, while the two bureaucratic components of the Egyptian-Israeli policymaking apparatus had conflicting opinions, the negotiating leadership of the two countries expressed unified support. Cases such as this are the reason the operations of the coalition should anticipate coordinating collaboration between branches and departments in the same government, in addition to their international projects.

By hosting these projects, and maintaining unprecedented continuity and collaboration between projects, the coalition will enable regional elites to develop a rapport. Incidents such as in 1978, when Israeli Prime Minister Menachem Begin called the Egyptian Foreign Minister a "young man" during a meeting, would be more easily avoided. ${ }^{89}$ Although the Prime Minister's intention was benign, the remark was considered condescending and after the Egyptian delegation departed it took months to reestablish a stable dialogue. Increased encounters between elites will foster better relationships in the long run, especially if they are part of a sustained regional effort.

Much of this work will be manifest in the form of regular meetings, policy forums, and summits, each with varying degrees of public access and international inclusiveness. As an organizational mechanism for these activities, the coalition should be organized around a Middle East Center for Cooperation. Although it is possible the Center for Cooperation could be established with a single headquarters, it may be necessary to create multiple regional offices.

\footnotetext{
${ }^{88}$ Spiegel 2004

${ }^{89}$ Spiegel 2004 p85
} 
Location aside, the importance of the Center for Cooperation is as a central (institutionally, not necessarily geographically) hub for coordinating regional track II projects. Much of the work undertaken by the Center for Cooperation would be divided between administrators at the various member organizations, at least until funding could be secured to found a separate institution, specifically tied to the coalition and operating in that central coordinating role. The work of the Center for Cooperation should be conducted digitally in the early years of the coalition, especially if a central location is not identified.

Although in the context of a track II coalition a central coordinating hub like the Center for Cooperation is unique, the idea is drawn from the organization structure of existing security regimes and many of the proposals for a regime in the Middle East. For instance, the Organization for the Prohibition of Chemical Weapons (OPCW) is the coordinating body for the CWC. The proposals for official regimes articulated by Evron and in the SIPRI report also call for central bodies for monitoring, coordination, dialogue, and enforcement. ${ }^{90}$ Most nearly related to the proposal for the Middle East Center for Cooperation is the regional security institute described by Spiegel. ${ }^{91}$ The security institute would provide NGO input on issues under discussion through official government negotiations.

The second component to the operations of the coalition relates to public opinion and the ability of NGOs to engage with and respond to the public. It is helpful here to recall figure two, which depicts the ways in which NGOs interact with the various components of the public. On this subject, operations must necessarily be bidirectional; the coalition should work to express public sentiments to governments, while also serving an educational role in their projects

\footnotetext{
${ }^{90}$ Evron 1999; Jones 2011

${ }^{91}$ Spiegel 2004
} 
involving the public. In both types of projects, consider Yankelovich's interpretation of public judgments; it will be important to refine public opinion to improve the quality of public judgments in order to make the expression of these judgments more compelling for government elites.

In 2000, Yasser Arafat refused to negotiate at Camp David because he perceived a significant opposition from the Palestinian public. He cited the growing popularity of Hamas and the Islamic Jihad as reasons for not making concessions in negotiations with Israel. ${ }^{92}$ It is easy to dismiss Arafat's behavior as ploy to strengthen his bargaining position. While in some instances this may be the case, both in the Middle East and elsewhere, to categorically dismiss appeals to public pressure would be overly cynical. Political officials feel the pressures of public opinion in a variety of ways, not at all limited to democratic elections. Under the status quo, the two most common expressions of public opinion in the Middle East are nonviolent and violent protest. The coalition would be positioned to provide an additional channel of communication. NGOs will be able to coordinate domestic survey initiatives to better evaluate public opinion on regional security issues. As part of a coalition, NGOs will be uniquely able to gather data from a variety of regional publics. One of the most challenging aspects to evaluating Middle East public opinion is the dearth of reliable data, so this function of the coalition will be tremendously valuable to analysts and policy makers. As the coalition matures, is recognized by more governments, and increases its work with the public, it will be possible to assist in coordinating petition campaigns. Petitions can be an excellent tactic in conveying public opinion. Similar efforts already exist through social media outlets, but they are organizationally weak and often

\footnotetext{
${ }^{92}$ Ibid p78
} 
unfocused. The coalition could provide legitimacy to these public activities and increase their effectiveness.

As the coalition will include research institutions in its membership, the coalition stands to make significant contributions to public opinion research beyond the limited confines of conveying public opinion to governments. In this sort of research endeavor, it is important to recall Surowiecki's four components in the correct interpretation of public opinion: information diversity, independence, decentralization, and aggregation. As previously discussed, public opinion research in the Middle East is hampered by the lack of reliable data (i.e. non-government sources). Of particular interest is the ability to better gauge the divides in public opinion between interest groups, cultures, age groups, geographical locations, and by socioeconomic status. The hope is that over time it will be possible to reproduce the sort of research provided by the Chicago Council on Foreign Relations, used earlier in reference to public decision-making and the role played by ideology in formulating public opinion. The structure of the coalition makes it the ideal entity for this sort of research as it meets with each of Surowiecki's four criteria. Undertaking this sort of work in the Middle East will both enhance the general understanding of public opinion, specifically as it relates to foreign policy, and it will help guide the educational programs sponsored by the coalition.

In addition to gauging public opinion, it is important that accurate information also flow in the opposite direction. To this effect, the coalition should host educational programs on all issues in which they engage. In reviewing track II projects since they came into their prime in the 1990s, it becomes clear that this is both one of the most important functions of an NGO project, and one of the worst executed. Most educational programs are intended for elite education; that is, academics, policymakers, etc. While these high level programs will still serve 
a purpose, they are no substitute for public engagement. Recall the stages of track II operations from Part I: socialization, filtering, and policy inaction. As identified earlier, the filtering process is usually where track II projects encounter the most problems. Traditionally, the filtering stage involves conveying the results of track II discussion from the isolated group of direct participants to their constituent governments. This version of filtering must be expanded in order to engage the public. The composition of the coalition should enable its various members to develop a balanced account of security issues which are too often mired in rhetoric and hyperbole. Media outreach, public forums, and pamphleting movements will serve as the mechanisms for public education. The success of these projects will help improve the quality of public judgments, which have been stunted in some places by state media and an overabundance of rhetorical expression.

With regard to public expression, part of the purpose of the coalition should be to move the manner of interaction between publics and governments from the bottom of the scale, nearer to the top (recall the five-tier account from before). Rather than resorting to violence, especially when the resort to violence is a fringe behavior and can delegitimize similarly minded peaceful activities, it should be possible to gradually work towards conditioning publics and governments to interact through peaceful means of public discourse. Much of this behavior would be empowered through democratic processes, but the existence of democracy should not be taken as a precondition.

While one of the primary functions of the coalition is to coordinate activities with regional governments, it is worth considering the manner in which extra-regional governments should be permitted to participate, particularly with regard to Western governments. Many NGOs in the ME already have connections with the West. However, Western officials should be 
limited in their ability to participate in the early stages of the coalition development. As the coalition develops, and a regionally representative group of states decides to participate, it will be possible to incorporate the limited involvement of western officials. Ideally, extra regional governments will only become involved when the coalition is strong enough, and has the favor and participation of enough regional governments, that serious talks can begin around an official regional security regime. At that stage it is not unusual to have extra regional stake holders become involved, if only to voice their support for the principles of the emerging regime. At the unofficial level, this sort of involvement would be less constructive as the primary goal of the coalition is to engage with regional publics and build relationships between regional elites. Foreign governments would have little to contribute, and their involvement would be more likely to derail early progress than to advance regional cooperation. This represents a significant divergence from the norms of the field; most considerations of Middle East security involve highly integrated participation from either the United States or European Governments. The difference of opinion is explained by the difference in approach. The types of participants in a track II coalition with the goals articulated above are necessarily different from those participants typically considered by isolated track II projects or official negotiating processes. The early stages of the coalition are intended for building regional relationships, and extra-regional influences are neither necessary nor conducive to achieving this goal. 


\section{Barriers to Success}

The evolution of the proposed coalition will not go unopposed. A prime example of overt interference was on display in late 2011 when Egyptian Security Forces halted the operations of 17 NGOs. ${ }^{93}$ This sort of government interference will certainly continue in many parts of the region. As the coalition develops, some projects will set it at odds with certain governments, particularly projects having to do with public engagement. It is likely that some coalition members will be prohibited from operating for periods of time, or will cease to exist entirely. This is of course a challenge already faced by many NGOs in the region, especially those working on security-related issues. As members of a coalition, with the support of at least some regional governments, it can be hoped that NGOs will be less likely to face restrictions by governments. This problem will be most pronounced in the early stages of development, but as the coalition grows, becomes better established, and gains regional support and representation, it will become increasingly difficult for governments to abuse NGO coalition members.

Government restrictions on NGOs are not necessarily overt. The efforts of the COE to promote citizenship rights in Europe involved collaboration between both governments and NGOs. In the case of Russian involvement addressed earlier in Part II, the Moscow School of Political Studies was one of the few NGOs permitted to participate in COE forums and workshops. ${ }^{94}$ However, after participating in these projects, the Moscow School was often shut out by the government and prevented from contributing to the policymaking process. This sort of barrier, although less overt, is in some ways more pernicious and threatening to the success of

\footnotetext{
${ }^{93}$ LA Times. December 29, 2011. "Egyptians Raid Offices of NGOS, Including U.S.-Based Groups". Accessed online at http://latimesblogs.latimes.com/world_now/2011/12/egyptian-authorities-raid-offices-of-ngos-includingus-based-groups.html. Last accessed May 4, 2012

${ }^{94}$ Checkel 1997 p484
} 
the coalition. Although the coalition will be able to pursue new collaborative research efforts and advocacy programs, their long term success is dependent on their ability to work with regional governments. Recall the remainder of Checkel's case study on the COE and the diffusion of citizenship norms. Given the changing governance conditions in parts of the Middle East, there is little to gain from trying to fit regional governments into Checkel's categories (state over society, statist, corporatist, and liberal). However, we can safely acknowledge that the region presents an array of states along the spectrum, although heavily concentrated on the statist end. Furthermore, as discussed earlier, the variances within each section should be taken into consideration. For instance, between two statist societies, one may have a particularly influential commercial industry with greater access to government officials than their domestic counterparts. Alternatively, instead of influential business elites, an example nearer to the circumstances faced in Russia could exist; an institution for higher education may be positioned to gain better access to members of the government than the likely limited NGO community. These considerations are important because they make clear the necessity of maintaining a diverse membership in the coalition. Some approaches will be successful in one country, but different circumstances leave them fruitless in others.

Of the many logistical concerns a new coalition will face, the most potentially damaging is the identification of funding sources. The startup costs of the coalition should be moderate, considering it will consist mostly of agreeing with other Middle East organizations on terms of collaboration and resource-sharing. As the coalition develops it will be necessary to identify additional funding sources to support the expanded projects. Returning to the Egypt example, of the 17 NGOs affected, two were based in the United States and were funded by Congress with the mission of monitoring democratic processes and promoting democratic values 
internationally. In this instance, the source of funding for the two NGOs influenced how they were perceived by the government. Among the NGO projects operating in the Middle East today, many are supported by Western governments. For instance, the CWCC is currently pursuing funding from a number of European governments to support an upcoming summit in the Middle East. The Coalition must be cognizant of their funding support, and how funding sources can inform both public and government perception of their activities.

The final barrier worth mentioning is the potential for government participation to gradually diminish as the coalition grows. As mentioned previously, the primary concern of the coalition is to facilitate dialogue and engage regional publics in security policy for the purpose of norm propagation and the improvement of public opinion. However, it must be noted that if the coalition persists in the absence of some display of concrete achievements, government willingness to participate may fade. Of the critiques included in this section this is the least worrisome, primarily because government officials are largely accustomed to getting very little accomplished, but also because the scope of the envisioned coalition will almost certainly obtain concrete policies in the tertiary areas of economics and the environment.

\section{Conclusions}

When track-II projects in the Middle East have occurred over the last two decades they function almost identically as their official counterparts, especially in cases where government representatives are present. Because they operate the same way, these projects are vulnerable to the same weaknesses inherent in government relations. State interests and entrenched rhetoric keep governments in the Middle East apart. Track-II programs ought to be able to capitalize 
more effectively on what makes them fundamentally different from official government programs; NGOs are not restricted by state interests, their current operations show a willingness to engage across the region, and their work makes an effort to transcend debilitating state rhetoric. In order to better realize the potential of these attributes it is necessary to forge a coalition of NGO partners that is regionally inclusive and that can lay a foundation for a future of stable government relations.

With such a variety of NGOs working in the Middle East, many of them with overlapping or complimentary missions, the only remaining question is why NGOs have not become better integrated already. To a large extent, this can be explained by the barriers to NGO projects identified at the end of Part II. However, as was also explained, by collaborating NGOs may mitigate some of the risks of acting independently. A more likely and more frustrating explanation is that the right people in the NGO community have yet to try.

The driving force behind this paper was dissatisfaction with existing literature evaluating track II projects, and perhaps even more so, the literature analyzing prospects for developing official Middle East security regimes. In the case of the former, contributors time and again identify the importance of altering the status quo security culture through track II projects, but then fall short of suggesting a proposal that would provide the longevity and consistency required do something as massively challenging as altering the political culture of an entire region. In the case of the latter, contributors call upon the spreading of "norms" and "culture" to explain the importance of some future security regime, but they do not adequately acknowledge the integral role of such norms in the establishment of a security regime. This paper is an attempt to address these shortcomings by providing a short-term recommendation for how to influence the long-term future of Middle East security. 


\section{Bibliography}

Achen, Christopher H. "Mass Political Attitudes and the Survey Response." American Political Science Review 69.4 (1975): 1218-31. Print.

Adler, Emanuel, and Peter M. Haas. "Conclusion: Epistemic Communities, World Order, and the Creation of a Reflective Research Program." International Organization 46.01 (1992): 367. Print.

Adler, Emanuel. "The Emergence of Cooperation: National Epistemic Communities and the International Evolution of the Idea of Nuclear Arms Control." International Organization 46.01 (1992): 101. Print.

Āghā, Husayn, and Shai Feldman. Track-II Diplomacy: Lessons from the Middle East. Cambridge, MA: MIT, 2003. Print.

Almond, Gabriel A. (1956). "Public Opinion and National Security Policy" Public Opinion Quarterly, Summer 1956, vol. 20, no. 2, p. 371-378 Print.

Basrur, R. M. "Nuclear Weapons and Indian Strategic Culture." Journal of Peace Research 38.2 (2001): 181-98. Print.

Bhargava, K. K., Heinz Bongartz, and Farooq Sobhan. Shaping South Asia's Future: Role of Regional Cooperation. New Delhi: Vikas Pub. House, 1995. Print.

Boutwell, Jeffrey, and Everett Mendelsohn. "The Middle East Security Environment." Bulletin of the American Academy of Arts and Sciences 49.3 (1995): 21-50. Print.

Caspary, William R. "The 'Mood Theory': A Study of Public Opinion and Foreign Policy."American Political Science Review 64.2 (1970): 536-47. Print.

Checkel, J. T. "International Norms and Domestic Politics: Bridging the Rationalist-Constructivist Divide." European Journal of International Relations 3.4 (1997): 473-95. Print.

Checkel, Jeffery. "Why Comply? Social Learning and European Identity Change." International Organization 55.3 (2001): 553-88. Print.

Checkel, Jeffrey. "The Constructivist Turn in International Relations Theory." World Politics 50.2 (1998): 324-48. Print.

Davies, John, and Edy Kaufman. Second Track/citizens' Diplomacy: Concepts and Techniques for Conflict Transformation. Lanham, MD: Rowman \& Littlefield, 2002. Print.

Dobbin, Frank. "Cultural Models of Organization: The Social Construction of Rational Organizing Principles." Ed. Diana Crane. The Sociology of Culture: Emerging Theoretical Perspectives. Oxford, UK: Blackwell, 1994. Print. 
Dupuy, Trevor N., and Gay M. Hammerman. A Documentary History of Arms Control and Disarmament,. New York: T.N. Dupuy Associates, 1973. Print.

Eagly, Alice Hendrickson., and Shelly Chaiken. The Psychology of Attitudes. Fort Worth, TX: Harcourt Brace Jovanovich College, 1993. Print.

Evans, Peter B., Harold Karan. Jacobson, and Robert D. Putnam. Double-edged Diplomacy: International Bargaining and Domestic Politics. Berkeley: University of California, 1993. Print.

Evron, Yair. "Confidence- and Security-building Measures in the Arab-Israeli Context." Contemporary Security Policy 16.1 (1995): 152-72. Print.

Finnemore, Martha, and Kathryn Sikkink. "International Norm Dynamics and Political Change." International Organization 52.4 (1998): 887-917. Print.

Garcia, Denise. "Disarmament Diplomacy and Human Security." Disarmament Diplomacy and Human Security: Regimes, Norms, and Moral Progress in International Relations. London: Routledge, 2011. Print.

George, Alexander L. "Domestic Constraints on Regimes Change in US Foreign Policy: The Need for Policy Legitimacy." Change in the International System. Ed. Ole R. Holsti, Randolph M. Siverson, and Alexander L. George. Boulder, CO: Westview, 1980. Print.

Goldman, Ralph. Arms Control and Peacekeeping: Feeling Safe in the World. New York: Random House, 1982. Print.

Herron, Kerry G., and Hank C. Jenkins-Smith. Critical Masses and Critical Choices: Evolving Public Opinion on Nuclear Weapons, Terrorism, and Security. Pittsburgh, PA: University of Pittsburgh, 2006. Print.

Ibrahim, S. E. "Future Visions of the Arab Middle East." Security Dialogue 27.4 (1996): 425-36. Print.

Intriligator, Michael D. "Arms Control and Confidence-Building in the Middle East: Policy Recommendations in Three Phases." Ed. Steven L. Spiegel and David J. Pervin. Practical Peacemaking in the Middle East. New York: Garland Pub., 1995. Print.

Jasper, James M. The Art of Moral Protest: Culture, Biography, and Creativity in Social Movements. Chicago: University of Chicago, 1997. Print.

Jervis, Robert. "Security Regimes." International Organization 36.02 (1982): 357. Print.

Jones, Peter. "Negotiating Regional Security and Arms Control in the Middle East: The ACRS Experience and beyond." Journal of Strategic Studies 26.3 (2003): 137-54. Print.

Jones, Peter. "Negotiating Regional Security and Arms Control in the Middle East: The ACRS Experience and Beyond." Ed. Zeev Maoz, Emily B. Landau, and Tamar Malz. Building Regional Security in the Middle East: International, Regional and Domestic Influences. London: Frank Cass, 2004. Print. 
Jones, Peter. "Filling a Critical Gap, or Just Wasting Time? Track Two Diplomacy and Regional Security in the Middle East." Disarmament Forum 2 (2008): 3-12. Print.

Jones, Peter. "The Arms Control and Regional Security Working Group: Still Relevant to the Middle East?" EU Non-Proliferation Consortium (2011): 1-15. Print.

Jones, Peter. Towards a Regional Security Regime in the Middle East: Issues and Options. Sweden: SIPRI, 2011. Print.

Jones, Peter. "Track II Diplomacy and the GWMDFZ." Security and Terrorism Research Bulletin 1 (2005): 15-18. Print.

Katzenstein, Peter J., Ronald L. Jepperson, and Alexander Wendt. "Norms, Identity, and Culture in National Security." Ed. Peter J. Katzenstein. The Culture of National Security: Norms and Identity in World Politics. New York: Columbia UP, 1996. Print.

Katzenstein, Peter J. The Culture of National Security: Norms and Identity in World Politics. New York: Columbia UP, 1996. Print.

Kaye, Dalia Dassa. Talking to the Enemy: Track Two Diplomacy in the Middle East and South Asia. Santa Monica, CA: RAND National Security Research Division, 2007. Print.

Kaye, Dalia Dassa. "Track Two Diplomacy and Regional Security in the Middle East." International Negotiation 6 (2001): 49-71. Print.

Khallaf, Tamim. "Seizing the Opportunity to Create a WMD-free Middle East." WMD Junction. James Martin Center for Nonproliferation Studies, 17 Apr. 2012. Web. 18 May 2012. <http://cns.miis.edu/wmdjunction/120417_mideast_wmdfz.htm>.

Klotz, Audie. Norms in International Relations: The Struggle against Apartheid. Ithaca: Cornell UP, 1999. Print.

Knopf, Jeffrey W. Domestic Society and International Cooperation: The Impact of Protest on US Arms Control Policy. Cambridge: Cambridge UP, 1998. Print.

Kowert, Paul, and Jeffrey Legro. "Norms, Identity, and Their Limits: A Theoretical Reprise." Ed. Peter J. Katzenstein. The Culture of National Security: Norms and Identity in World Politics. New York: Columbia UP, 1996. Print.

Kraig, Michael. "Assessing Alternative Security Frameworks For the Persian Gulf." Middle East Policy 11.3 (2004): 139-56. Print.

Krasner, Stephen D. International Regimes. Ithaca: Cornell UP, 1983. Print.

Krause, Keith, and Andrew Latham. "Constructing Non-proliferation and Arms Control: The Norms of Western Practice." Contemporary Security Policy 19.1 (1998): 23-54. Print.

Landau, Emily. Egypt and Israel in ACRS: Bilateral Concerns in a Regional Arms Control Process. Tel Aviv: Jaffee Center for Strategic Studies, Tel Aviv University, 2001. Print.

Lippmann, Walter (1922) Public Opinion. New York, Harcourt, Brace and Co. 1922 
Lupia, Arthur, and Mathew D. McCubbins. The Democratic Dilemma: Can Citizens Learn What They Need to Know? Cambridge, U.K.: Cambridge UP, 1998. Print.

McDonald, John W., and Diane B. Bendahmane. Conflict Resolution: Track Two Diplomacy. Washington, D.C.: Foreign Service Institute, U.S. Dept. of State, 1987. Print.

Moravcsik, A. "Explaining International Human Rights Regimes:: Liberal Theory and Western Europe." European Journal of International Relations 1.2 (1995): 157-89. Print.

Moravcsik, Andrew. "Liberal Intergovernmentalism and Integration: A Rejoinder." JCMS: Journal of Common Market Studies 33.4 (1995): 611-28. Print.

Morgan, Patrick M. "Regional Security Complexes." Ed. David A. Lake and Patrick M. Morgan. Regional Orders: Building Security in a New World. University Park, PA: Pennsylvania State UP, 1997. Print.

Nadelmann, Ethan A. "Global Prohibition Regimes: The Evolution of Norms in International Society." International Organization 44.04 (1990): 479. Print.

Nolan, Janne E. Global Engagement: Cooperation and Security in the 21 st Century. Washington, D.C.: Brookings Institution, 1994. Print.

Oldendick, Robert W., and Barbara Ann Bardes. "Mass and Elite Foreign Policy Opinions." Public Opinion Quarterly 46.3 (1982): 368-82. Print.

Page, Benjamin I., and Jason Barabas. "Foreign Policy Gaps between Citizens and Leaders."International Studies Quarterly 44.3 (2000): 339-64. Print.

Piven, Frances Fox. Challenging Authority: How Ordinary People Change America. Lanham, MD: Rowman \& Littlefield, 2006. Print.

Pregenzer, Arian. "The Cooperative Monitoring Center: The First Ten Years." International Security News 4.3 (2004): 2-21. Sandia National Laboratories, July 2004. Web. 1 Mar. 2012. <http://www.cmc.sandia.gov/isn/jul04isn.pdf>.

Pruitt, D.G. "Ripeness Theory and the Oslo Process." International Negotiation 2.23 (1997): 237-50. Print.

Ripberher, J.T., T.M. Rabovsky, and K.G. Herron. "Public Opinion and Nuclear Zero: A Domestic Constraint on Ditching the Bomb." Politics and Policy 39.6 (2011): 891-923. Print.

Rosenau, James N. National Leadership and Foreign Policy; a Case Study in the Mobilization of Public Support. Princeton, NJ: Princeton UP, 1963. Print.

Rosenau, James N. Public Opinion and Foreign Policy; an Operational Formulation. New York: Random House, 1961. Print.

Sharp, Paul. "For Diplomacy: Representation and the Study of InternationalRelations." International Studies Review 1.1 (1999): 33-57. Print. 
Sikkink, Kathryn. "Human Rights, Principled Issue-networks, and Sovereignty in Latin America." International Organization 47.03 (1993): 411. Print.

Simon, Sheldon W. "Evaluating Track II Approaches to Security Diplomacy in the Asia-Pacific: The CSCAP Experience." The Pacific Review 15.2 (2002): 167-200. Print.

Snow, David A., R. Burke Rochford, Jr., Steven K. Worden, and Robert D. Benford. 1986. "Frame Alignment Processes, Micromobilization, and Movement Participation." American Sociological Review 51: 464-481.

Solingen, Etel. "Domestic Aspects of Strategic Postures: The Past and Future in a Middle East Nuclear Regime." Ed. Efraim Inbar and Shmuel Sandler. Middle Eastern Security: Prospects for an Arms Control Regime. Portland, Or.: Frank Cass, 1995. Print.

Spiegel, Steven L. "Regional Security and the Levels of Analysis Problem." Ed. Zeev Maoz, Emily B. Landau, and Tamar Malz. Building Regional Security in the Middle East. London: Frank Cass, 2004. Print.

Stedman, Stephen John., Donald S. Rothchild, and Elizabeth M. Cousens. Ending Civil Wars: The Implementation of Peace Agreements. Boulder, CO: Lynne Rienner, 2002. Print.

Surowiecki, James. The Wisdom of Crowds: Why the Many Are Smarter than the Few and How Collective Wisdom Shapes Business, Economies, Societies, and Nations. New York: Doubleday, 2004. Print.

Taylor, Michael. "When Rationality Fails." Ed. Jeffrey Friedman. The Rational Choice Controversy: Economic Models of Politics Reconsidered. New Haven [u.a.: Yale Univ., 1996. Print.

Wapner, Paul Kevin. Environmental Activism and World Civic Politics. Albany: State University of New York, 1996. Print. SUNY Ser. in International Environmental Policy and Theory.

Warkotsch, Alexander. "The OSCE as an Agent of Socialisation? International Norm Dynamics and Political Change in Central Asia." Europe-Asia Studies 59.5 (2007): 829-46. Print.

Wittkopf, Eugene R. Faces of Internationalism: Public Opinion and American Foreign Policy. Durham: Duke UP, 1990. Print.

Yaffe, Michael D. "Promoting Arms Control and Regional Security in the Middle East." Disarmament Forum 2 (2001): 9-25. Print.

Yair, Evron. "Toward the Emergence of a Common Security System in the Middle East." Ed. Lenore G. Martin. New Frontiers in Middle East Security. New York: St. Martin's, 1999. Print.

Yankelovich, Daniel. Coming to Public Judgment: Making Democracy Work in a Complex World. Syracuse, NY: Syracuse UP, 1991. Print. 